\title{
La Portugalización de Brasil
}

\begin{abstract}
PHILIPPE C. S CHM ITTER es actualmente profesor asociado en la Universidad de Chicago. Hizo su licenciatura en la Universidad de Ginebra y doctorado en la Universidad de California en Berkeley y ha sido profesor visitante en el Instituto de Ciências Sociais de la Universidad de Brasil en Río de Janeiro, el Instituto para la Integración de América Latina en Buenos Aires y la Universidad de Harvard en Cambridge, Mass. Es autor de numerosos trabajos sobre integración regional, un libro sobre la política de grupos de interés en Brasil (Interest Conflict and Political Change in Brazil, Stanford University Press, 1971) y varios análisis cuantitativos sobre dependencia y la política contemporánca latinoamericana.
\end{abstract}

La toma del poder por los militares brasileños en 1964, fue saludada. por algunos sectores como un acto casi sin precedentes en la historia: del mundo libre. Estos defensores autoproclamados de la democracia: liberal pueden haber tenido razón, pero por motivos equivocados. EI curso de los acontecimientos, desde entonces, se ha movido en dirección opuesta: hacia la institucionalización de un régimen autoritario permanente. Sea deliberadamente o no '(y veremos que hay creciente evidencia de que se trató de un proceso intencional), los gobernantes militares brasileños han seguido políticas que han privado a muchos hombres públicos y ciudadanos activos de su autonomía, han reducido el campo de las soluciones políticamente permisibles y han eliminado toda consecuencia del sistema que no sea la de su propia perpetuación en el poder. Al hacerlo así, han revivido un modelo de desarrollo político que parecía haber quedado. históricamente desacreditado.

Portugal, habiendo demostrado previamente la viabilidad (y los. costos) de este tipo de respuesta a las presiones provenientes de un proceso de modernización y desarrollo, ha suministrado lo que se podría llamar el "arquetipo" de este típico sistema de dominación. política autoritaria. De aquí el concepto de "portugalización" aplicado al proceso a través del cual clicho régimen es institucionalizado. Un signo de interrogación en el título de este ensayo tendría el propó-. sito de sugerir que todavía no es posible excluir la posibilidad de que el sistema conduzca a resultados diferentes, aunque están dis- 
minuyendo las probabilidades de que esto ocurra. Todavía no se ha logrado una institucionalización completa; persisten incompatibilidades estructurales sin resolver; los valores de la élite y las aspiraciones populares todavía no se han ajustado al nuevo modelo emergente. Este ensayo está, en efecto, inspirado en la proposición de que a través del análisis especulativo $y$ evaluativo sería posible convencer a los brasileños de las consecuencias políticas del camino que ellos han emprendido. Estamos esperanzados en que esto estimulará la resistencia frente a un destino que, irónicamente, muy pocos de ellos anhelan o merecen ${ }^{1}$. Infortunadamente, hay muy pocos signos de que. la tendencia hacia la portugalización pueda ser detenida. Está intoxicante mezcla de optimismo irreal y de improvisación real, $\tan$ bien captada por Fernando Pereira en la frase "oportunismo histórico", parece una vez más haber calado hondo en el curso del desarrollo político brasileño, no obstante las buenas intenciones y la valerosa acción política de muchos. Temo que el dicho popular "ninguem segura este pais" - nadie detiene a este país- bien podría ser correcto, aun si lo que se tratara de detener fuera un sistema permanentemente poco representativo.

Al evaluar el curso de los gobiernos imperantes desde 1964, he rescogido deliberadamente el empleo de aquellos criterios de evalua"ción del comportamiento del sistema que los propios representantes del movimiento "revolucionario" han establecido $y$, en gran medida, han suministrado. Me propongo enfrentarlos, al menos parcialmente, en su propio terreno: en aquellos sectores de la política gubernativa y de la acción social que ellos prefieran. No criticaré ni condenaré dichos gobiernos a causa de ser bien conocidos en la prensa mundial por sus repetidas violaciones a los derechos universales del hombre y a las propias normas constitucionales autoimpuestas por ellos. Los actos de arresto arbitrario, pérdida de derechos politicos, censura de prensa, restricciones al derecho de reunión, destitución de académicos, exilio forzoso, intimidación física y tortura han quedado documentados en forma abundante y convincente. Por mucho que me repela hacerlo, aceptaré (o, mejor dicho, suspenderé mi increduliclad a este respecto) el argumento oficial de que esas "medidas de excepción" hubieron de ser adoptadas, contra la voluntad del régimen, a causa de las actividades terroristas desplegadas por grupos minoritarios $y / o$ ejecutadas por pequeños grupos locales de policías y, militares "entusiastas", sin

${ }^{1} \mathrm{Cada}$ régimen militar posterior a 1964 se ha comprometido públicamente con la democratización (y después han seguido políticas antitéticas a ese fin). Para la más reciente de éstas, ver el compromiso del Presidente Médici para "la construcción de una sociedad políticamente abierta" en su discurso en la Escuela Superior de Guerra (ESG). Jornal do Brasil, 11 de marzo de 1970. 
el conocimiento o la connivencia de las autoridades centrales. En efecto, como argüiré más adelante, el uso indiscriminado de la arbitrariedad y del terror por parte de los funcionarios públicos es. incompatible con la institucionalización de un régimen autoritario. El espionaje intensivo y extensivo y un eficiente servicio nacional de información pueden cumplir la misma función de incapacitar e inhibir a los opositores del régimen a un costo mucho menor y: menos visible.

Mi evaluación comenzará con un examen del comportamiento de ciertas políticas -el modelo de decisiones que emplea el sistema político para asignar y distribuir recursos- y de los resultados de las mismas políticas - los resultados. netos o concatenados de una multiplicidad de acciones más los factores contextuales que alteran el comportamiento global del sistema. Un régimen determinado puede ser responsabilizado directamente por los cambios acaecidos en el primero de estos planos como, por ejemplo, por los aumentos o disminuciones en los gastos educacionales o militares, pero difícilmente puede adjudicársele todo el crédito o la censura por lo que ocurra en el segundo de ellos, por ejemplo, en la tasa de crecimiento económico o de inflación. Aquí el analista está obligado a considerar las "alternativas no factuales": ¿Podría haberse producido el mismo resultado en ausencia de todo cambio en el comportamiento de las políticas gubernativas?

Por consiguiente, trataré de relacionar esas políticas y sus consecuencias indirectas con la configuración futura del sistema político, en la medida en que ellas realimentan el proceso económico, politico y cultural y, de esta manera, fortalecen o debilitan la distribución del poder y de los privilegios existente. En tal sentido, formularé la pregunta -o mejor dicho, estipularé en ausencia de datos confiables - acerca de quién se ha beneficiado y quién se está beneficiando con el régimen y de qué manera la distribución actual de los beneficios públicos y privados podría afectar el futuro del sistema político brasileño. En particular, con base en investigaciones anteriores, identificaré ciertos componentes estructurales básicoś del "sistema" creado por Getulio Vargas y trataré de establecer cómo se están desarrollando bajo la tutela militar.

\section{ALGUNAS DIVERGENCIAS INTERPRETATIVAS}

El tema principal de este ensayo está indicado:en la frase previa. Por mi parte, sostengo que para entender la dinámica y las consecuencias probables de la dictadura militar existente en Brasil desde 1964 es necesario considerar esta dictadura en relación con lọs 
regímenes autoritarios que existieron anteriormente en el país, aunque hayan sido de naturaleza diferente. Expresado simplemente, mi argumento consiste en que los militares "revolucionarios" tomaron el poder como una reacción frente a la decadencia ( $y$ al colapso inminente) de ese sistema autoritario preexistente, y que buscaron a continuación (en forma un tanto caprichosa y quizás inconsciente) purgar ese sistema de algunos de sus elementos contradictorios, especialmente de su "populismo" $y$ cle su carácter relativamente "competitivo". Al hacerlo, ellos se han aproximado en forma mucho más estrecha al régimen autoritario "puro" ejemplificado por España ${ }^{2}$ y Portugal. La relativa facilidad y éxito cle sus esfuerzos encaminados a "purificar" el sistema pueden ser parcialmente explicados por el hecho de que ellos fueron capaces de construir sobre estructuras institucionales $y$ pautas de comportamiento precedentes.

Tal interpretación pugna con la visión mucho más ortodoxa que subraya la naturaleza aberrante y discontinua de la "revolución". De acuerdo con esta versión, en 1945 Brasil rompió con su autoritario pasado fascistoide (considerado en sí mismo como una aberración) y comenzó un nuevo experimento democrático, ejemplificado por la adopción de una nueva constitución liberal y la revitalización de un sistema competitivo de partidos y de un dinámico proceso legislativo. Los años siguientes vieron una gradual expansión de la participación política y electoral y una progresiva democratización de las instituciones, y el país pareció avanzar firme e ineluctablemente por el camino liberal y pluralista que previamente habian recorrido los Estados Unidos y el norte de Europa. ${ }^{3}$ El golpe de 1964 se debió, al menos en parte, a una "crisis de participación", pero las implicaciones de este análisis (escasamente explicitado por sus expositores norteamericanos, pero claramente enunciado a manera de justificación por algunos de los afortunados golpistas) radican en que el régimen militar es un simple expediente, un corto interludio durante el cual habrán de resolverse los problemas ocasionados por la distorsión institucional y una asimilación insuficiente, problemas que se reflejaron especialmente en el choque entre un presidente populista y un congreso tradicional de clientela. Superada esta aberración,

'Juan Linz, An Authoritarian Regime: Spain, en E. Allard y S. Rokkan (editores), Mass Politics (Nueva York: The Free Press, 1970), páginas 251-283.

${ }^{3}$ Este tema, si bien con limitaciones, ha sido presentado más persuasiva $y$ extensamente en Thomas Skidmore, Politics in Brazil, 1930-1964: An Experiment in Democracy (Nueva York, Oxford University Press, 1967). Para un estudio que destaque la naturaleza gradualista de la expansión del cuerpo electoral, ver a Joseph L. Love, Political Participation in Brazil, 1881-1969, en Revista LusoBrasileña, VI (diciembre de 1970), paiginas 3-24. 
Brasil volvería nuevamente a su curso histórico "natural" de desarrollo politico liberal y pluralista.

Una segunda perspectiva analítica cle carácter general, muy difundida entre los intelectuales radicales, aplica las categorias marxistas ortodoxas al golpe de 1964 y subraya su naturaleza contrarrevolucionaria. ${ }^{4}$ En efecto, ellos sostienen que el golpe fue un intento de "volver hacia atrás la aguja del reloj" más bien que de "ponerlo en la hora". De acuerdo con esta versión, los militares que se apoderaron del gobierno eran el instrumento de una coalición de intereses capitalistas urbanos y rurales, con ramificaciones nacionales e internacionales, endurecidos o radicalizados por la emergencia de un nacionalismo revolucionario. La crisis, que no sería simplemente el producto de un conflicto cultural entre el Brasil moderno y el Brasil tradicional, se habría generado primariamente en la conscientización de las masas y en la polarización de la lucha de clases. Los moderados fueron sumergidos en el campo contrarrevolucionario debido a una combinación de factores en que jugaron el miedo a la proletarización, exacerbado por la inflación, la clependencia económica frente a la clase capitalista y un anticomunismo histérico alimentado por la propaganda norteamericana y los medios de comunicación brasileños. Nuevamente, las implicaciones de esta interpretación apuntan a que, en última instancia, las masas no pueden ser desconocidas y el régimen militar no puede ser otra cosa que un expediente temporal e inútil.

A pesar de estas diferentes interpretaciones cle las causas que motivaron la crisis de $1964 \mathrm{y}$, particularmente, de la significación del régimen de Goulart, ambas perspectivas son fundamentalmente optimistas en el largo plazo. Ambas insisten en la naturaleza "extraordinaria", "discontinua" o "transitoria" del régimen autoritario del Brasil. Más allá de esto, estas interpretaciones incluso especifican por qué es probable que el régimen militar resulte inviable y se vea obligado a ceder el poder. En un escenario liberal y pluralista, ellos serían forzados por las aspiraciones políticas y las legítimas expectativas del pueblo brasileño, especialmente de las clases medias, a retornar a la democracia representativa. En un escenario socialista y revolucionario, las políticas aplicadas por las autoridades militares y sus servidores tecnocráticos tenderían a concentrar los beneficios en un grupo más estrecho aún que en el pasado, provocando la polarización de las fuerzas políticas y el derrocamiento del régimen por

4Para una cxposición más detallada y articulada de esta posición, ver Octavio Ianni, Crisis in Brasil (Nueva York: Columbia University Press, 1970). También en una vena más polémica, ver Miguel Arraes, Le Brísil, le peuple et le pouvoir (París, Maspero, 1969). 
las masas sublevadas. Los actuales gobernantes del Brasil no contarian, en ninguno de esos planos, con la esperanza de desafiar en forma permanente la marea de la historia contemporánea. Ellos no podrían detener los cambios estructurales de la sociedad y de la economía e incluso, en la misma medida en que lograran detenerlos, erosionarían la base social de su régimen autoritario.

Con base en mis investigaciones sobre los intereses políticos, he especulado con que ambos escenarios, derivados de la experiencia de Europa Occidental o de Norteamérica, podrían estar erróneamente especificados. Confiando fuertemente en el análisis de Karl Marx sobre el Bonapartismo en el Dieciocho de Brumario y en el diseño efectuado por Barrington Moore, Jr. (ver en la p. 7), de un camino capitalista y reaccionario hacia la modernización para las sociedades en desarrollo (Alemania, Italia y Japón), 5 desde el punto de vista de la comprensión teórica del fenómeno, y buscando información. empírica en los trabajos de intelectuales brasileños tales como Fernando Henrique Cardoso, Luciano Martins, Leoncio Martins Rodriguez, Caio Prado Junior, y Celso Furtado así como en mis propios estudios acerca de la representación de intereses corporativos, llegué a la conclusión de que puede haber una afiniclad deliberada entre los atributos que presenta la estructura y el comportamiento de un desarrollo retrasado y dependiente, por una parte, y un sistema autoritario permanente por la otra.

No es éste el lugar para reiterar toda mi argumentación. Esquemáticamente, especulé con que ciertas características de la postergada. transformación económica y social de Brasil hayan conspirado para hacer altamente difícil la repetición de un camino revolucionario hacia la modernización política ya sea liberal y plurista o nacionalista y colectivista. Por una parte, la urbanización preindustrial, los bajos niveles de empleo en las fábricas, la industrialización por sustitución de importaciones, la estagnación dual en el sector rural y una aguda dependencia frente al capital y la tecnología extranjera parecieron haber confundido algunas de las principales contraposiciones, desde el punto de vista de los intereses y las actitudes, que suministraron el dinamismo político a los primeros desarrollistas. Por sobre todo,

${ }^{5}$ Karl Marx, El Dieciocho de Brumario de Luis Bonaparte (Nueva York: International Publishers, 1963). También de pertinencia dirceta son The Class Struggles in France, 184S-1S50 (Nucva York: International Publishers, 1964) y The Civil War in France (Nucva York: International Publishers, 1940). Para un resumen útil e inteligente de Marx $y$ otros escritores del Bonapartismo, ver H. C. F. Mansilla, Faschismus und eindimensionale Gescllschaft (Neuwied u. Berlin: Luchterhand, 1971), páginas 137-145. El debate de Barrington Noore acerca de la "revolución desde arriba" y el "capitalismo reaccionario" se encuentra en su Social Origins of Dictatorhisp and Democracy' (Boston: Bcacon Press, 1966), páginas 228-253, 433-452. 
esos diferentes factores contextuales tendieron a fragmentar y a debilitar la conciencia de clase e incluso la sensibiliclacl de grupo de los. principales conglomerados dificultando el establecimiento y la mantención de movimientos, particlos o asociaciones agresivos. Por otra parte, una prolongada independencia política formal, una burocracia prematuramente ampliada y tasas cle inflación y de expansión económica sostenidamente elevadas habían contribuido a fortalecer la capacidad y la autonomía de las instituciones estatales preexistentes y, de esta manera, a capacitarlas para responder a los grupos de protesta emergentes o latentes, mediante la precoz extensión de los privilegios, la cooptación o la amenaza a los líderes más promisores, la concesión preventiva de beneficios económicos y protección social, el estímulo. a la corrupción generalizada y al favoritismo selectivo y, por supuesto, ejerciendo una esporáclica pero efectiva represión sobre los opositores más intransigentes."

Si estas amplias especulaciones de parte mía son correctas, si existealguna afinidad deliberada entre el desarrollo retrasado y dependiente de Brasil y el régimen autoritario del período 1930-1945, si el período de posguerra puede ser interpretado con ventaja como una tentativa para adaptar un sistema político básicamente autoritario a las exigencias mínimas de la democracia formal sin modificar sus estructuras. esenciales (en mi léxico, una democradura), si el período 1960-1964 puede ser apreciado correctamente como una expresión de la decadencia o desintegración de aquel sistema y de un creciente vacío de poder en sus centros, ${ }^{\tau}$ entonces los regímenes militares desde 1964

${ }^{a}$ Los detalles de este argumento estín señalados en mi Interest Politics and Political Change in Brazil (Stanford, California: Stanford University Press, 1971), páginas 366-376. Recientemente, he pensado probar algunas de estas suposiciones. a través del análisis del conjunto de datos de veinte repúblicas latinoamericanas. Consultar: Delayed Development, External Dependence and Political Change in Contemporary Latin America, documento presentado en la Reunión Anual de ISA, San Juan, Puerto Rico, marzo de 1971.

De paso, esto sugiere que las maniobras abortivas de Janio Quadros en 1960-61, podrían ser interpretadas como una tentativa para restablecer la estructura del sistema autoritario, mientras to hacia compatible con una base populista social diferente de la que había apoyado al getulismo. Este punto de interpretación está bien apoyado por la cronologia clescriptiva en John W. F. Dulles: Unrest in Brazil (Austin, Texas University Press, 1970), páginas 101-140. Es interesante que Carlos Castello Branco, el columnista político de Brasilia, recientemente hay'a argumentado que "las actividades frustradas del $\mathrm{Sr}$. Janio Quadros ... esencialmente se proponfan una reforma modelo de cuño autorilario que, en un cierto grado, fue realizada por la Constitución de 1967". Señalaba que lo que estaba ausente del modelo de Janio Quadros era una política exterior más independiente $y$ el hecho de que el régimen de Médici parecía estar trabajando hacia ella (Jornal do Brasil, 21 de setiembre de 1970). En mi concepto, tanto Janio Quadros como Médici han tratado de establecer el sistema autoritario sobre la base de una llamada mesoi, las masas urbanas medias. Con- 
(dictablandas en mi vocabulario) no deben ser definidas como tentativas revolucionarias o contrarrevolucionarias sino básicametne "restauracionistas".

Como tales, ellos no son intrínsecamente ilegítimos. Tampoco son agudamente discontinuos, excepto en relación con su predecesor inmediato de corte protopopulista o protosocialista, dependiendo del punto de vista de cada uno. Tales regímenes pudieron, en consecuencia, apoyarse sustancialmente sobre las estructuras de dominación y de representación establecidas e inspirarse en la mentalidad y en las pautas políticas y culturales prevalecientes. En breve, introduciendo relativamente pocos cambios institucionales y purgando el sistema de ciertas prácticas contradictorias (por ejemplo, libertarias) mientras mantenían una fachada formal prácticamente idéntica, los militares brasileños pudieron institucionalizarse en el poder y transmitirlo a los sucesores que ellos mismos digitaron, incluso civiles, si así lo querían. 8

Bajo esas condiciones, uno no podría anticipar fuertes resistencias - de parte de los sectores burgueses y medios empapados en las tradiciones del liberalismo político y encolerizados por haber perdido algo que nunca tuvieron: la hegemonía o la participación autónoma en el sistema político. Tampoco podría uno esperar que las organizaciones trabajacloras desafiaran seriamente a las autoridades con demandas militantes dirigidas a obtener una mayor igualdad, el acceso a los medios de producción o a la socialización de los mismos, en Iugar de preocuparse con la mantención de los beneficios que ya les habian sido concedidos benevolentemente desde arriba.

En lugar de eso, se podría predecir un modelo de participación y cle acomodación más característico de un sistema autoritario estableciclo: apoyo proveniente de una burguesia o de una clase poseedora

sultar a Francisco Welfort, Raices Sociales del Populismo en San Paulo, en Revista de Civilizaçĩo Brasileña. Año 1, No 2 (mayo, 1965), páginas 39-60, pues cn esta clase característica se basa el movimiento populista de Janio Quadros y de Adhemar de Barros.

${ }^{8}$ Para la primera declaración intelectual de reconocimiento de que los miliitares de 1964, estaban buscando imponer su propio modelo institucionalizado en la sociedad brasileña, evadiendo Ios roles de "militar salvador" o de "instrumento de clases", ver Candido Mendes, Sistema Politico e Modelos de Poder no Brasil, Dados, (I966), paiginas 7-41. También e igual, O gobermo de Castelo Branco: parodia e prognose. Dados, 2/3 (1967), páginas 63-111, y Elite de Poder, Democracia e Desenvolvimento, Dados, 6 (1969), páginas 57-90. Todos estos trabajos han tenido influencia en la estructuración de mi pensamicnto en este -documento, aunque tiendo a subrayar mucho más los elementos de continuidad con el sistema getuliano previo y mucho menos las diferencias entre "castelismo" y el "bonapartismo" de Costa e Silva. 
que ha trocado voluntariamente sus pretensiones a la hegemonía política por la seguridad económica, su "derecho a gobernar" por su "derecho a hacer dinero"; 9 consentimiento por parte de unos sectores medios no manuales, dependientes y asalariados, cuyos intereses son protegidos frente a las tendencias hacia la proletarización y la inflación, y la redistribución del ingreso, y cuyos empleos son asegurados por un extenso aparato burocrático de planificación y de control; aquiescencia de parte de una clase trabajaclora urbana relativamente privilegiada, protegida por una legislación social mínima de ser desplazada por las masas marginalizadas, representadas desde arriba por "líderes" designados o cooptados y vigiladas por unos gobernantes benevolentes deseosos de "hacer felices a las clases bajas dentro del marco de la sociedad burguesa (dictando) nuevos decretos que escamotean por anticipado a los 'verdaderos socialistas' su capacidad para gobernar". 10 Complementando estas abigarradas bases de apoyo social pasivo, existe una ideología oficialmente promovida o, mejor dicho, una mentalidad que enfatiza objetivos neutrales y difusos (el bien público) los que parecerían beneficiar igual y simultáneamente a todo el pueblo: el desarrollo y la grandeza nacional. ${ }^{11}$

La piedra angular de esta construcción autoritaria es aquello a que Marx se refiere como "die veselbständigten Machte der Exekutivgewalt" -aproximadamente traducido como "el proceso a través del cual el poder ejecutivo llega a ser progresivamente más independiente". No puedo resistir la tentación cle citar el siguiente párrafo tomado del Dieciocho de Brumario, por su extraordinaria aplicabilidad al Brasil contemporáneo:

Es obvio de inmediato que en un país como Francia, donde el poder ejecutivo controla un ejército de oficiales que alcanza a más

${ }^{9}$ El Dieciocho de Brumario, páginas 67, 106-107. "No identificándose subjetivamente con el gobierno, porque en parte no está objetivamente vinculado con él, los empresarios (brasileños) obtienen el máximo de beneficios por ser la clase dominante económicamente sin ser el estrato políticamente dominante", Fernando H. Carcloso: Empresario Industrial e Desenvolvimento Económico (San Paulo, Difusión Europea del Libro, 1964), página 168. Para una mayor exposición teórica de la inferencia de esta cliferenciación entre los intereses de clase públicos y privados, ver August Thalheimer, Uber den Faschismus, en O. Bauer, H. Marcuse u A. Rosenberg (editores), Faschismus und Kapitalismus (Frankfurt, Europaesche Verlagsanstalt, 1967), páginas 19-38. También R. Griepenburg u K. H. Tjaden, Faschismus and Bonaparlismus, Das Argument (1964), páginas $461-472$.

${ }^{10} \mathrm{El}$ Dieciocho de Brumario, página 132.

${ }^{11}$ Espalda con espalda en los principales discursos en la Escuela Superior de Guerra y en el Ministcrio de Relaciones Exteriores (Itamarati), el Presidente Médici destacó sólo esos temas, primero desarrollo y luego una política exterior independiente, Jormal do Brasil, I1 de marzo de 1970 y 21 de abril de 1970. 
de medio millón de inclividuos $\mathrm{y}$, por consiguiente, mantiene constantemente una inmensa masa de intereses insubsistencias en la más. absoluta dependencia; donde el estado atrapa, controla, regula, supervisa y vigila a la sociedad civil en sus detalles más insignificantes, descle las maneras más generales de ser hasta la existencia privada de los individuos; donde a través de la centralización más extraordinaria este cuerpo parasitario adquiere una ubicuidad, una omnisciencia, una capacidad para la movilización acelerada y una elasticidad que encuentra su contrapartida solamente en su irremediable dependencia, en el carácter vagamente amorfo del cuerpo político - resulta obvio que en un país como éste la Asamblea Nacional enajena toda influencia afectiva cuando pierde el control de las posiciones ministeriales, si al mismo tiempo no simplifica la administración del estado, reduce el ejército profesional en la medida de lo posible y, finalmente, permite a la sociedad civil y a la opinión pública crear órganos propios, independientes del poder gubernamental.12

El resultado eventual, nuevamente en la expresiva fraseología de Marx, consiste en que "la pugna parece terminar de tal manera que todas las clases, igualmente impotentes e igualmente mudas, caen de rodillas ante el culatazo del fusil". ${ }^{13}$ En lo social, el marco estructural indispensable para este "poder ejecutivo independiente" es uno en que haya emergido a la superficie de la vida política un agudo conflicto concordante con la estructura de clases, ejemplificado por revueltas urbanas u ocupaciones de fábricas (como en el París de 1849 y en Munich, Budapest y Turín en 1919-1920) o la violencia ruraI (como las ocupaciones de tierra en el valle del Po en 1919), pero en el cual, clebido a la fragmentación interna y/o a la dependencia externa, ninguna de las clases contendientes es capaz de imponer su modelo de ordenamiento politico a las otras. "En realidad, esta era la única forma de gobierno posible en un periodo en que la burguesía ya había perdido, y en que la clase trabajadora aún no había. adquirido, la facultad de regir la nación".14 En ese tenso vacío de poder se introducen los hombres providenciales, y proceden a gobernar y a consolidar su autoridad mediante una combinación de estratagemas (empujando a las clases divididas y temerosas unas contra otras) y represión (incorporando el ejército al proceso y construyendo una elaborada red de espionaje policial). El punto esencial de mi teoría acerca del desarrollo retrasado y dependiente consiste,

2:Obra citada, página 61-62.

'Moidem, página 121.

${ }^{14}$ Guerra Civil en Francia, página 56. 
precisamente, en que este contexto multiplica grandemente la probabilidad de una estructura de clases balanceada, impotente y no hegemónica.

Mi análisis diverge agudamente del de Marx, sin embargo, en un aspecto crucial: la permanencia o persistencia del régimen autoritario en cuestión. Marx concibió claramente al Bonapartismo como algo inédito y "moderno", pero definidamente como algo transitorio. La heterogeneidad de sus bases, su tanteo confuso y experimental con distintas políticas, su corrupción interna y sus especulaciones "estilo invernadero" lo llevarían a su caída. En último término, Bonaparte no podría mantener su imagen de benefactor patriarcal de todas las clases, en suma, no podría "dar a una clase sin quitarle a otra":

Impulsado por las exigencias contradictorias de su propia situación y estando al mismo tiempo, como un conjurador, bajo la necesidad de atraer la atención pública hacia él como un sustituto de Napoleón brindando constantes sorpresas, es decir, bajo la necesidad de ejecutar un golpe de estado en miniatura cada día, Bonaparte arrojó en la confusión toda la economía burguesa, violó todo lo que parecía inviolable en la revolución de 1848, hizo a algunos tolerantes frente a la revolución y a otros deseosos de ella, y produjo la anarquía actual en nombre del orden, mientras que al mismo tiempo, despojando de su halo a la maquinaria del estado, la profanó y la hizo al mismo tiempo repugnante y ridícula. ${ }^{15}$

Las implicaciones de este análisis es que tales políticas podrían empujar a la burguesía a reafirmar la hegemonía política que en un momento negociaron a cambio de una seguridad económica de muy corta vida. ${ }^{16}$

${ }^{15}$ El Dieciocho de Brumario, página 135. Para una interpretación de la RevoIución Brasileña que destaque la base social reaccionaria de su incapacidad para vencer los obstáculos estructurales, la inevitable asociación con el estancamiento de la economía (pastoralización), y por lo tanto su inviabilidad política, ver Celso Furtado, Obstacles to Development in Latin America (Garden City, Nueva York, Anchor Books, 1970), páginas 113-200. Marx, estaba menos dispuesto a esta clase de ilusiones pero él también exageró la vulnerabilidad de este tipo de sistema, por razones que sugiero más adelante.

19Yo también difiero de estos análisis ortodoxos marxistas, basados en una defectuosa interpretación del modelo bonapartista de Mirr, quien interpretó el nacimiento del fascismo y del nacismo como la última etapa del desarrollo del capitalismo, para ser sucedida, por supuesto, por el comunismo revolucionario. Siguiendo a Thalheimer, interpretaría el sistema autoritario como parte del proceso de consolidación del capitalismo más bien que como un síntoma de su muerte inminente. Consultar: en el rol transformacional del fascismo en el caso español, J. Solé-Tura, The Political "Instrumentality" in Fascism, en J. Woolf (editor), The Nature of Fascism (Nueva York: Vintage Books, 1969), páginas 42-50, 57. 
Mirando hacia atrás, puede decirse que Marx estuvo equivocado, al menos en lo que a la perspectiva temporal se refiere. Napoleón III presidió una sostenida transformación económica en Francia y fue finalmente derrocado, veinte años más tarde, debido solamente a su derrota en una guerra internacional. Desde entonces, el desarrollo de la tecnología política y material han hecho mucho más fácil el establecimiento y la implantación de un conjunto coherente de políticas gubernativas; captar la oposición emergente a través de indicadores sociales $y / 0$ encuestas directas, y actuar preventivamente; regimentar la actividad política dentro de un solo partido oficial; institucionalizar el sistema de representación de intereses; retener el monopolio de los agentes de la violencia organizada, y socializar e indoctrinar a los ciudaclanos a través de los medios de comunicación. y la educación de masas.

No quiero dar a entender que, dada su "afinidad celiberada" con el contexto de un desarrollo retrasado y dependiente y la naturaleza cambiante de la técnica política, los regímenes autoritarios no pueden ser depuestos una vez entronizados en el poder. Probablemente no. me habría molestado en escribir este ensayo si hubiera tenido esta visión tan rígidamente determinista y pesimista acerca del futuro de tales regímenes. ${ }^{17}$ Creo que el reconocimiento de estas proclividades. e interdependencias es un requisito previo para montar estrategias de resistencia efectivas. Por mucha ilusión que se tenga en los ideales. libertarios de las clases medias o por grandle que sea la fe en la vocación escatológica del proletariado, ello no será suficiente para operar la transformación de este tipo de régimen. Es preciso idear nuevas estrategias, basadas en las contradicciones y debilidades de este tipo. particular y característico de sistemas políticos. En las notas finales. formularé algunas sugerencias en este sentido; permítaseme por ahora, sin embargo, concentrarme en el examen del comportamiento de las. políticas del régimen.

COMPORTAMIENTO DE LAS POLÍTICAS DEL RÉGIMIEN DESDE 1964

Entre 1964 y 1967, el régimen de Castelo Branco dictó cerca de seis. mil decretos y decretos leyes. Costa e Silva, en menos de dos años,

El locus classicus, de este argumento es Frant Borkenau, Zur Soziologie des. Faschismus, en Ernst Nolte (cditor), Theorien über den Faschismus (Koln: Kiepenheur und Witsch, 1967), páginas 156-181.

${ }^{17}$ Aqui yo subrayaría este argumento hecho por los humanistas de la Alemania moderna. Mientras la defunción del régimen de Goulart (o República de Weimar), puede haber sido inevitable, lo que por ningún motivo era inevitable es que lo 
sobrepasó los cuatro mil, ${ }^{18}$ y el actual gobierno de Médici bien podría sobrepasar esas marcas de productividad legislativa. Doce actos institucionales, 62 actos complementarios (de acuerdo con mi último. cómputo) y una nueva constitución reformada dentro de 24 horas, indican las dificultades con que se tropieza al tratar de resumir brevemente el modelo de formulación de políticas seguido por los. restauracionistas "revolucionarios". Pareceria imposible seguir una pista coherente a través de esa inmensa masa de decretos que modifican otros decretos, frecuentemente modificatorios de otros decretos. todavía, sin mencionar el gran número de "lays que não pegarme". En todo caso, tal tarea me llevaría más allá del foco temático de este ensayo.

Por consiguiente, me concentraré en algunas áreas generales de politicas de especial significado para la institucionalización clel régimen autoritario. Todas esas áreas contribuyen de una manera particularmente estratégica a la independización del ejecutivo. Ellas son: 1) el rápido establecimiento de una base de recursos amplia y bien equilibrada para el aparato estatal; 2) una creciente penetración de la economía por los instrumentos estatales de subvenciones y control, y 3) fuertes desembolsos en defensa exterior y seguridad interna. Posteriormente, discutiré aquellas áreas de políticas más específicas que han contribuido al fortalecimiento de estructuras más especializadas en el régimen autoritario como, por ejemplo, el corporativismo, la centralización, la despolitización y el sistema monopolístico de partidos.

Uno de los principales objetivos políticos proclamados abiertamente por los "revolucionarios" de 1964 fue el de restaurar la salud y el equilibrio de la economía, así como también purgar el sistema político de elementos corruptos y subversivos. Como un medio para este fin (o, para algunos, como un fin en sí mismo), los autores de la revolución promulgaron una serie de reglas que tuvieron el efecto de restaurar y aun de expandir la base económica y la autoridad del estado, así como su penetración en el sector privado. ${ }^{10}$ Aquellos defensores del golpe que to miraron como la oportunidad histórica para detener el estatismo, reduciendo el papel y los recursos de las instituciones gubernamentales intervencionistas, tenían que verse

que le seguiría sería la "portugalización" o "nazificación". Consultar: Theodor Eschenberger y otros, The Path to Dictatorslsip, 19,1S-1933 (Garden City, Nueva York, Anchor Books, 1966), página XVII.

${ }^{28}$ The Law Will Rule, Brasil, 1969 (Nueva York: Centro para Relaciones Interamericanas, 1970), página 144.

${ }^{19}$ APEC, A Economia brasileira e suas Perspectivas, IX (julio de 1970), página $\mathrm{F}-\mathrm{]}$. 


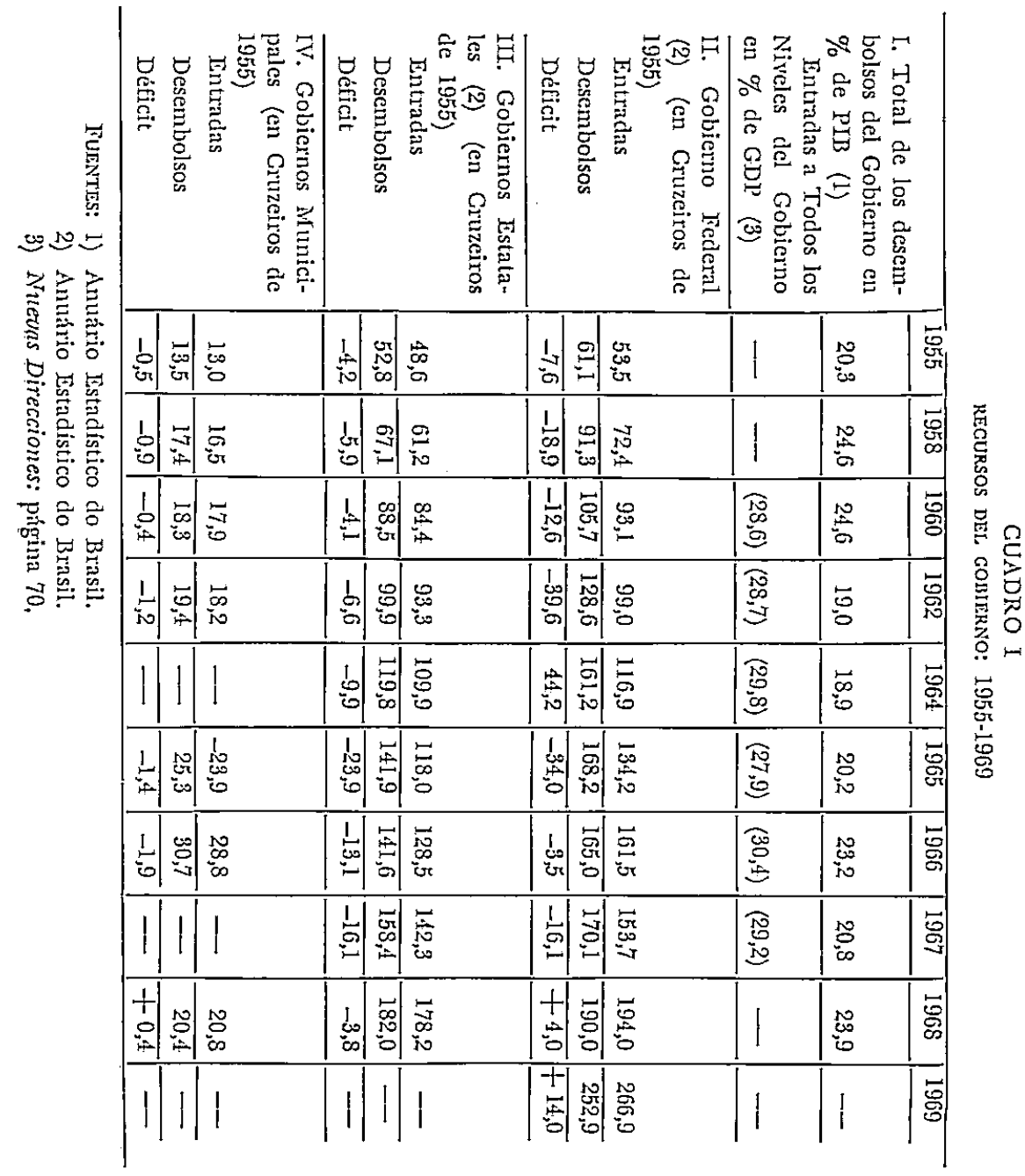


frustrados. Los editoriales de El Estado de São Paulo, en los años siguientes, son un testimonio elocuente de este liberalismo frustrado.

El cuadro I revela muy claramente la recuperación financiera del país. Cualesquiera que sean los otros cargos que puedan formularse contra el régimen de Goulart, éste obtuvo una disminución sustancial de los gastos públicos totales como porcentaje del PIB. Desde la época de Kubischek, en que alcanzaron la proporción de $24.6 \%$ (1958$1960)$, dichos gastos disminuyeron a $19.0 \%$ y $18.9 \%$ (1962, 1964). Los gastos gubernamentales, a todos los niveles, han aumentado nuevamente en 1965, y hacia 1968 habian alcanzado aproximadamente los niveles de la época anterior a Goulart. Aunque no he podido obtener información correspondiente al PIB para 1969, los gastos del gobierno federal representaron el $19 \%$, programándose un incremento del $45 \%$ para 1970.20 Las cifras relativas al déficit son de especial importancia en el cuadro I. En el año crítico de 1964, casi una tercera parte de los gastos totales del gobierno estaban en el rojo. Con la excepción de una ligera recaída en 1967, las autoridades "revolucionarias" no solamente salvaron esa brecha sino que incluso lograron acumular excedentes en 1968 y 1969 . Y es importante subrayar que esto no fue acompañado por un programa de liberalización draconiano o por una política de austericlad en el uso de los recursos fiscales, sino que por una expansión de los ingresos más acelerada que la de los gastos y por una transferencia de estas cargas a los contribuyentes (véase cuadro III).

GUADRO II

IMPUESTOS TOTALES COMO PORCENTAJE DEL PRODUCTO BRUTO INTERNO

\begin{tabular}{llllllllll}
\hline 1955 & 1958 & 1960 & 1962 & 1964 & 1965 & 1966 & 1967 & 1968 & 1969 \\
\hline 15,8 & 20,1 & 20,3 & 18,0 & 19,5 & 22,0 & 24,4 & 21,7 & - & - \\
\hline
\end{tabular}

Fúnte: Gonjuntura Económica, 171 (1970), página 45 ,

¿Cómo está siendo financiada esta rehabilitación? ¿Sobre quién está descansando el peso del gasto fiscal? Una de las más pregonadas políticas del régimen ha sido el fortalecimiento del proceso de recaudación de impuestos a la renta. El espectro de los amedrentados ciudadanos de las clases media y alta, pagando por primera vez impuestos

${ }^{2}$ The Economic Intelligence Unit, Quarterly Economic Reviews, Brazil, Ne 4 (1969), p. 9. 
directos, ha sido empleado por el régimen, interna y externamente, para vigorizar su imagen de neutralidad y eficiencia tecnocrática. No hay duda de que los impuestos a la renta se han elevado, incluso astronómicamente, habiendo experimentado un aumento de $70 \%$ solamente en 1968. Sin embargo, lo que no se ha destacadó tanto es la "racionalización" introducida en muchos impuestos indirectos de carácter regresivo. El cuadro III muestra claramente que éstos han

\section{CUADRO III}

INGRESOS TOTALES DEL GOBIERNO CENTRAL POR VÍA IMIPOSITIVA 1961-1968

\begin{tabular}{rrrrrrr}
\hline Entradas & sin & impuesto & \multicolumn{2}{c}{ Impuestos indirectos } & \multicolumn{2}{c}{ Impuestos directos } \\
\hline 1961 & 1968 & 1961 & 1968 & 1961 & 1968 \\
\hline 10,3 & 1,9 & 62,8 & 76,7 & & 29,9 & 21,4 \\
\hline
\end{tabular}

Fuente: Banco Interamericano de Desarrollo, Progreso Socio-Económico en América Latina, Fondo Fiduciario de Progreso Social, Noveno Informe Anual, Washington, D. C., 1969, página 74.

crecido proporcionalmente mientras que los ingresos no tributarios, como las utilidades de las empresas estatales, se han reducido a nada y otros impuestos directos han disminuido proporcionalmente, como habría ocurrido con el impuesto a la propiedad. Si bien una fuente diferente muestra que este último se elevó de $28.7 \%$ de las recaudaciones totales en 1964 a $34.3 \%$ en $1967,{ }^{21}$ al colocar este fenómeno en un contexto más amplio se llega a la conclusión de que los ricos fueron "exprimidos" en mucho menor medida que los pobres.

Sin embargo, se han efectuado cambios importantes, y el régimen no sólo ha adquirido una fuente de recursos más diversificada sino que ha demostrado también su capacidad para imponer nuevos gravámenes sobre aquellos que son sus principales beneficiarios y partidarios. La reforma tributaria de 1969 exigió que se registraran todos los brasileños, ganaran o no lo suficiente para pagar impuesto, y bajó las tasas de tributación para los grupos de ingresos medianos y más bajos. Lo que es más importante, esta reforma redujo las tasas que afectan a los poseedores de acciones y ofreció fuertes exenciones a quienes invirtieran en determinados proyectos o sectores, garantizados por el gobierno. ${ }^{22} \mathrm{EI}$ resultado de todas estas maquinaciones consistió

${ }^{21}$ Las cifras citadas están basadas en mis cálculos de datos de entradas del gobierno federal en IBGE, Anuário Estadistico do Brasil, 1955-1969.

22" ¿La Economía Bajo Control?", Brasil, 1969, páginas 10-11. 
en reducir cualquier impacto redistributivo que hubiera podido tener: la reforma fiscal primitiva y colocar en manos de las autoridades un nuevo y poderoso conjunto de instrumentos, si bien indirectos, para orientar el ahorro y la inversión. En un sentido paradojal $-\mathrm{y}$, uno podría argüir, también perverso- fue necesario crear un sistema de impuesto sobre la propiedad y los ingresos, a la vez confiable y eficiente, con el objeto de poder aplicarlo parcialmente y de esta manera fortalecer el control potencial del gobierno sobre la economía, por condescendencia.

¿Dónde han sido asignados estos recursos públicos restablecidos. y aumentados? ¿Cuál ha sido la distribución de los gastos federales por parte de los sectores burocráticos? ¿En qué medida puede decirse que estos mecanismos reflejan y refuerzan el control autoritario sobre el proceso de formulación de políticas?

En un análisis reciente, sobre la başe de datos lineales, acerca del comportamiento de las políticas de 18 repúblicas latinoamericanas para el periodo 1950-1967, descubrí algunas interesantes asociaciones al respecto. Pude así concluir que ciertas características def régimen -control civil vs. militar, sistema de partidos competitivos vs. no competitivos- tienen un efecto independiente significativo sobre la forma de recaudar los recursos públicos y de distribuirlos por sectores. Las características del régimen, en cambio, tienen un efecto mucho menor sobre el comportamiento de las políticas que tienen que ver con la tasa global de crecimiento de la economía y con la inflación, aunque ellas estén relacionadas con pautas características de violencia $e$ inestabilidad política. ${ }^{23}$

Uno de los hallagzos del estudio fue la confirmación de lo que ya había observado a nivel regional latinoamericano: los regímenes militares no competitivos confían más fuertemente en los impuestos indirectos de carácter regresivo. Otro descubrimiento fue que este tipo de regímenes tiende a gastar más recursos para fines de seguridad nacional y menos para educación y bienestar. Concediendo que el concepto de "régimen militar y no competitivo" no es sinónimo de régimen autoritario (siendo el primero un sistema puramente expeditivo o "salvacionista", en el lenguaje de Cándido Méndez, mientras que el último puede ser civil o militar), en todo caso es preciso reconocer que la institucionalización del régimen autoritario parece requerir el apoyo de un grupo militar satisfecho y unificado $y$ la presencia de un gran aparato policial interno para

${ }^{23}$ Military Intervention, Political Competitiveness and Public Policy in Latin America, documento presentado en el Congreso ISA, Varna, Bulgaria (Setiembre de 1970), que aparecerá en un volumen sobre Fuerzas Armadas y Sociedad, editado. por Jacques Van Doorn. 
fines de información y seguridad. Dado que otra de sus características es una rígida reglamentación corporativista, especialmente para las asociaciones laborales, es posible también anticipar una relativa falta de interés en expandir los gastos en bienestar, destinados al sector de los trabajadores, o una falta de preocupación por el tema, más allá de un grado mínimo de atención caritativa y paternalista y de algunos gestos de ayuda ocasionales, realizados desde arriba, de carácter preventivo.

El cuadro IV confirma estas afirmaciones. Los gastos en defensa, que se recuperaron rápidamente después de 1964, alcanzaron su cúspide en 1967, cuando llegaron a contarse entre los más altos de América Latina. Desde entonces, estos gastos se han consolidado -e incluso en alguna medida han declinado proporcionalmente, sino ,en términos absolutos. A la inversa, los gastos del Ministerio de Traibajo y Seguridad Social han experimentado una permanente declinación secular, hasta el punto de que en el presupuesto de 1970 esa secretaría recibió menos que el Ministerio de Justicia. Los gastos en salud se han comportado en forma igualmente anémica en manos de las 'autoridades "revolucionarias".

Las cifras sobre gastos en educación provenientes del ministerio federal confirman una observación hecha anteriormente en un plano comparativo. No parece haber diferencias significativas en los gastos en educación efectuados por regímenes civiles o militares, competitivos o no competitivos. En el cuadro IV encontramos que estos regímenes se comportan, en este plano, de una manera sorprendentemente estable, con la excepción de pequeños cambios "progresivos" entre 1965 y 1968 . Desde entonces, el ministerio de educación y cultura ha vuelto a sus porcentajes habituales, de 6.2 al $6.8 \%$, en el presupuesto general. Tomando en cuenta el aumento de los gastos globales del gobierno, lo anterior significa un mayor volumen de recursos en cifras absolutas ${ }^{24}$ y, como veremos, también han habido importantes cambios cualitativos.

RESULTADO DE LAS POLÍTICAS A. PARTIR DE 1964

Estos son los indicadores que permiten juzgar a los gobernadores militares del Brasil contemporáneo. Después de atravesar por un oscuro período de desgaste entre 1964 y 1966, en que las políticas de austeridad y de saneamiento monetario estuvieron asociadas con

sxara una exposición más detallada, ver Richard Weisskoff y Francine Weisskoff, The Brazilian Educational System. 


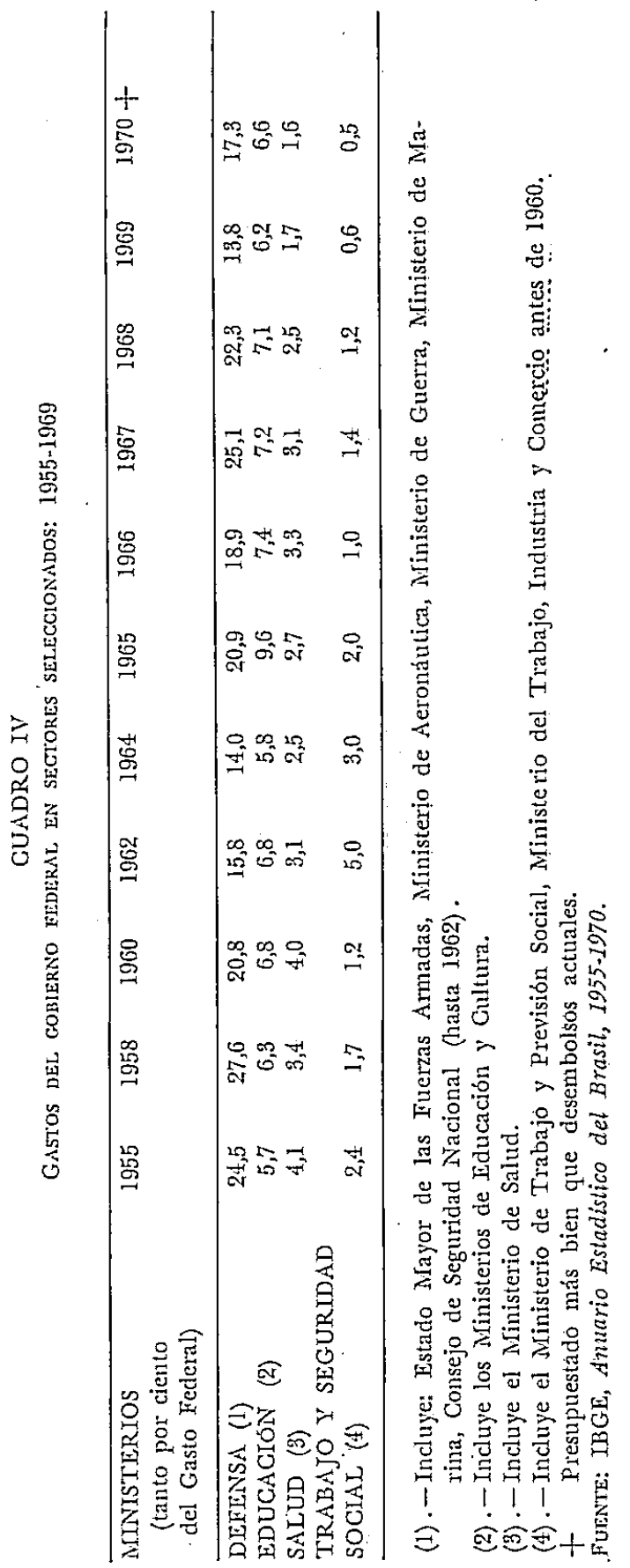


tasas de crecimiento per cápita negativas o escasamente positivas, y en el cual la inflación continuó aumentando a un ritmo superior al $40 \%$ por año (un período de cuya información, por lo demás, presenta disparidades considerables y algunas trazas de prácticas fraudulentas), el régimen parece haber visto por fin la luz del día. Mientras que antes tales resultados fueron juzgados como "lamentables pero inevitables" ahora el régimen está haciendo lo posible para contabilizar en su favor unas tasas de crecimiento anual de alrededor de $9 \%$ (y aun mayores en la industria) junto a la contención de las tasas de inflación (24\%).

Podria parecer tendencioso señalar que su confesión de culpa original estaba bien fundada. Por ejemplo, la investigación comparativa a que hacía referencia más arriba mostró que las tasas de crecimiento alcanzadas en los últimos años eran en gran medida predecibles a la luz de factores estructurales y ecológicos, tales como los niveles anteriores de desempleo y el grado y tipo de dependencia externa del país, y que fueron afectadas bien poco por las características del régimen e incluso por sus políticas ${ }^{25}$. También podría parecer poco honesto observar que la expansión económica de los últimos tres años, en buẹna medida, solamente sirvió para restablecer en el Brasil la tendencia iniciacla en los años 1950, antes de que ese crecimiento fuera interrumpido por la decadencia de un sistema político y el movimiento restauracionista.

Ninguno de estos puntos es efectivamente relevante. Sean meritorios o no, los actuales gobernantes del país y los ciudadanos parecen encontrarse convencidos de que su variedad de gobierno autoritario - y solamente ella- resultan compatibles con tan altos niveles de comportamiento del sistema. La competencia partidista, la autonomía de los grupos de interés, el liderazgo populista demagógico y la polarización ideológica de los años 1960 a 1964 han llegado a ser asociados con los resultados opuestos. Aquellos que se opondrían a la institucionalización del régimen autoritario se ven forzados a reconocer que éste debe ser asociado con un período de dinamismo económico en comparación con el periodo anterior, como ocurrió con la Francia Bonapartista. Estó tiende, a su vez, a garantizar altos niveles de optimismo popular frente al futuro, lo que es especialmente cierto en el caso de Brasil ${ }^{26}$ : Por ejemplo, en una encuesta reciente de San Pablo (diciembre de 1970), el $75 \%$ de los encuestados pen-

25 Ibidem, páginas 29-30, 53 y 57.

${ }^{2}$ Consultar a Lloyd A. Free, Some International Implications of the Politic Psychology of Brezilians (Princeton, Nueva Jersey: Institut for International Social Research, 1961). También, Frank Bonilla, "Brasil", en J. S. Coleman (editor), Education and Political Development (Princeton: Princeton University Press, 1965), páginas 195-221. 


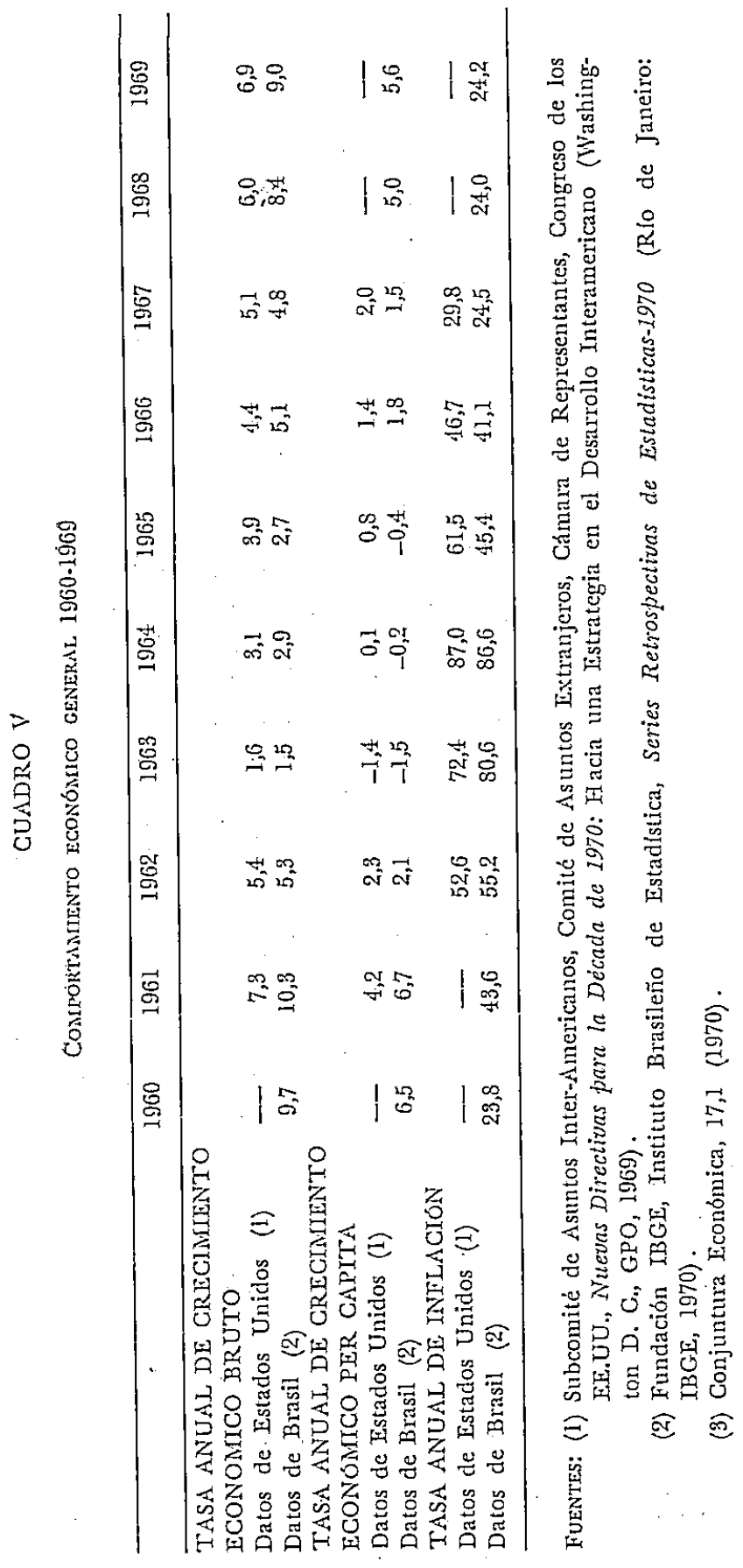


saba que 1971 sería mejor que 1970 , y el $73 \%$, que 1971 sería un año más próspero pero con paz social en las industrias $(76 \%)$ y más empleo $(75 \%)$. El gráfico que acompañaba dicha encuesta, basado en respuestas formuladas a las mismas preguntas de este 1967, demostraron una tendencia secular hacia un creciente optimismo ante el futuro ${ }^{27}$. Bajo tales condiciones, parecería tácitamente suicida que un movimiento de oposición se basara en profecías sobre un inminente desastre económico, y estratégicamente erróneo depender de la materialización de contradicciones de largo plazo entre el crecimiento económico y el régimen autoritario.28

Otra pregunta planteada por los paulistas, sin embargo, nos lleva a un punto verdaderamente crucial en el largo plazo: la distribución de esa aparente bonanza. Al ser interrogados acerca de si su nivel personal de vida había subido, caído o continuado, el $48 \%$ dijo haber subido, el $7 \%$ haber disminuido y el $45 \%$, haber permanecido igual. La respuesta fue superior a la de 1969,1968 y 1967 , cuando el $41 \%$, el $33 \%$ y el $30 \%$, respectivamente, pensaban que su nivel de vida había mejorado. Sin embargo, ello ilustra una deficiencia básica en este modelo de crecimiento de "invernadero", autoritariamente promovido: su gran desigualdad. Hasta cierto punto, y por un tiempo limitado, los brasileños pueden sentir un orgullo vicario por el obvio dinamismo de su país, pero eventualmente ellos comenzarán a interrogarse: "¿Qué es lo que me toca?".

Los datos sobre distribución del ingreso en Brasil no son fáciles de hallar, para ponerlo en forma suave, especialmente sobre la base de series cronológicas coherentes ${ }^{29}$. Afortunadamente, sin embargo, el "Departamento Intersindical de Estadistica e Estudos Socio-Económicos (DIEESE), un organismo de investigación independiente, localizado en San Pablo y financiado por los sindicatos, ha estado recolectando información sobre el nivel de vida de la clase trabajadora allí. Sus estimaciones rigurosamente compiladas muestran una importante disminución en el poder de compra durante los primeros dos años del régimen militar, ligeramente mitigada por algunos progresos en 1968-1969. El total cumulativo para los primeros cinco años arroja una declinación de $31.5 \%$. Pero este cálculo alarmista está basado sólo en una yuxtaposición formal de indicadores sobre costo de vida

27" ¿Por qué se ufanan de 1970?", Veja, 6 de enero de 1971.

${ }^{28} \mathrm{G}$. Celso Furtado, obra citada. Esta parte del texto original fue publicada en Brasil bajo el título más explícito: Um Projeto para o Brasil (Río: Editora Saga, 1968). Para un excelente estudio de los cambios de política bajo el sistema autoritario, ver Charles Anderson, The Political Economy of Modern Spain (Madison, Wisconsin University Press, 1970).

${ }^{29}$ Para datos mejores $y$ más al día en la distribución de los ingresos, ver el ensayo de Albert Fishlow en el volumen mencionado en la nota 23. 
y aumentos salariales decretados por el gobierno. De acuerdo con esto, mientras que el salario mensual promedio en 1969 habría sido. de 430.83 nuevos cruceiros, las encuestas del DIEESE muestran que el salario real habría sido de sólo 345.06 nuevos cruceiros. Aparentemente los empleadores, aprovechándose de la debilidad de la clase trabajadora y de sus sindicatos y valiéndose de los nuevos artificios. legales ofrecidos por las autoridades "revolucionarias", habrían evitado exitosamente el pago de los aumentos. El resultado pudo ser una declinación del poder de compra de los trabajadores en los. principales centros industriales del país, de un $64.5 \%$ desde $1958^{30}$. Una comisión investigadora parlamentaria documentó también esedeterioro, en noviembre de 1969. Incluso el embajador de los Estados. Unidos en Brasil admitió, en esa época, que "cuatro años y medion después de la revolución, los salarios reales de los trabajadores eran inferiores que en marzo de $1964 .{ }^{31}$

\section{CUADRO VI}

CAMBIO ANUAL PROMEDIO EN EL PODER DE COMPRA DE LOS TRABAJADORES DE SAN PAULO: 1965-1969.

\begin{tabular}{ccccc}
\hline 1965 & 1966 & 1967 & 1968 & 1969 \\
\hline$-15,3 \%$ & $-15,6 \%$ & $-5,6 \%$ & $0,3 \%$ & $1,1 \%$ en tantos por cientos. \\
\hline
\end{tabular}

Fuente: "DIEESE en Resumen", Año IV, No 3 (Marzo de 1970).

GUADRO VII

Distribución REgIONAL DE LA RENTA NACIONAL BRUTA: 1939-1966

\begin{tabular}{lrrrr}
\hline & 1939 & 1950 & 1960 & 1966 \\
\hline & & & & \\
I. - Norte & 2,66 & 1,71 & 2,23 & 2,11 \\
II. - Noreste & 16,73 & 14,65 & 14,78 & 14,36 \\
III. - Sureste (MG, ES, RJ, GB, SP) & 62,91 & 65,56 & 62,77 & 63,06 \\
IV. - Sur & 15,56 & 16,29 & 17,77 & 17,32 \\
V.-Centro Oeste & 2,14 & 1,79 & 2,49 & 3,12 \\
\hline
\end{tabular}

Fuente: Realidade (Julio de 1970), página 87. Fuente original: Centro de Cuentas Nacionales, IBRE/FGV.

${ }^{30}$ DIEESE en resumo, Año IV, NQ 3 (Marzo de 1970).

${ }^{31} J$ ohn Tutthill, Economic and Political Aspects of Development in Brazil.. Journal of Inter-American Studies, XI (Abril, 1969), página 208. 
También hay índices indirectos "aproximados" del empobrecimiento de las clases bajas. El consumo per cápita de carne disminuyó de 41 kilos en 1961 a 39 kilos en 1967. El consumo de azúcar también descendió, mientras subían los "alimentos del pueblo", el arroz y los frejoles ${ }^{32}$. El único signo brillante en ese triste cuadro dietético fue un alza sustancial en el consumo de leche; de acuerdo con las propias estimaciones del gobierno sobre el costo de vida, el porcentaje de la renta total gastado en alimentos subió de 40.3 a $41.2 \%$, desde la "revolución". Según la ley de Engels, esa proporción debía haber bajado si la prosperidad global de la nación hubiera aumentado ${ }^{33}$. En una situación financiera crecientemente restrictiva, las familias. se vieron obligadas a gastar proporcionalmente más, simplemente para sobrevivir. Al igual que Alicia, ellos corrían a toda velocidad para permanecer en el mismo lugar.

Hay otras grietas en la "expansión" experimentáda desde 1968: la creación de nuevos empleos y las contrataciones declinaron y la oferta de trabajo permaneció estagnada; el consumo de electricidad no aumentó tanto como la producción global. Lo anterior indica, tal vez, la importancia que tuvieron las manipulaciones puramente financieras y especulativas. Lo que es más serio; todo ello ha contribuido significativamente a agravar otra disparidad: la que existe entre las distintas regiones de Brasil. Como muestra el cuadro VII, entre 1960 y 1966 se revirtió la tendencia de la década anterior hacia una mayor participación del nordeste y en el ingreso nacional. Cabe aceptar que algo de ello puede haberse debido a ciertas prácticas anteriores al golpe militar, pero no hay muchas indicaciones de que la administración postrevolucionaria de la superintendencia para el nordeste del Brasil (SUDENE) haya teniclo éxito en sus esfuerzos para invertir la corriente. De hecho, un ministro del interior, el general Albuquerque Lima, renunció en ostensible protesta frente a la baja prioridad acordada al nordeste por el plan de desarrollo del régimen. Un sistema especial de condonación de impuestos logró canalizar hacia el norte algunas inversiones privadas ${ }^{34}$. Pero con el establecimiento de sistemas similares para otras regiones y sectores,

"Eufemisticamente, los funcionarios económicos sugieren que la declinación en carne $y$ azúcar fueron debidas a "razones de naturaleza médica". Conjuntura Econōmica, 17,1 (1970), página 12.

${ }^{3}$ Ibidem, página 11. Este artículo observa que el incremento no se habría debido al cambio de los precios de los alimentos que realmente declinaron relativo a otros precios.

${ }^{34}$ Consultar a Albert O. Hisschman, Industrial Development in the Brazilian Northeest and the Tax Credit Scheme of Article 34118, en The Journal of Development Studies, Volumen l (Octubre de 1968), páginas 5-28. El proyecto, por supuesto, antecede a la captura del poder por los militares en varios años $\langle 1961-1963\rangle$. 
y con el extraordinario auge de la cotización de los valores industriales en los mercados de capital cle las regiones más desarrolladas del país, incluso ese paliativo tendió a perder importancia. La solución final a la cual aparentemente se ha llegado para el nordeste es la reubicación de campesinos mediante la construcción de la carretera transamazónica. De hecho, las obras respectivas se iniciaron con base en grandes grupos de trabajadores compuestos por víctimas de las sequías.

El indicador más alarmante que he visto de los resultados de las políticas del régimen está relacionado con la evolución de la distribución del ingreso en las capitales de los estados nordestinos. De acuerdo con una investigación emprendida por el Banco del Nordeste, el porcentaje de la renta total que obtiene el cuarenta por ciento de la población de Recife de más bajos ingresos, disminuyó del $16.5 \%$ en 1960 al $11.5 \%$ en 1967. Los datos correspondientes a Maceió muestran incluso más claramente los efectos de la revolución. En abril de 1964, dicho cuarenta por ciento percibía el $15.4 \%$ de la renta, pero sólo lograba retener el $11.2 \%$ de ella en marzo de 1968. Una sola de las ocho capitales envueltas en el estudio experimentó un aumento en el ingreso per cápita de los sectores más postergados de la región más deprimida del país ${ }^{35}$. En ninguna parte podría encontrarse una prueba más convincente del hecho, por lo demás admitido por el gobierno del Brasil, de que "a économia pode ir bem, mas a maioria do povo ainda vai mal"36. Desgraciadamente, tampoco existe evidencia de un esfuerzo coordinado del régimen para invertir esta creciente desigualclacl.

\section{LOS COMPONENTES ESTRUCTURALES DEL RÉGIMIEN AUTORITARIO}

La premisa principal en que se fundan mis comentarios introductorios es que existe una "respuesta autoritaria al desafío de la moclernización de tipo muy definido: un conjunto homogéneo, interdependiente y relativamente estable de instituciones y prácticas politicas que permiten a las élites administrar, conducir, o manipular la transformación de las estructuras económicas y sociales al mínimo costo posible para ellos, en términos de poder, riqueza y prestigio.

${ }^{35}$ Banco del Noreste, "Distribução e Niveis da Renda Familiar no Nordeste Urbano", Fortaleza, Ceara, Diciembre de 1969, como se reseña en APEG, $A$ Economia brasileira e suas Perspectivas, IX (Julio de 1970), páginas 187-198. Por otro lado se informó que en Recife un quinto de los principales devengadores de entradas incrementó su participación de un 47,1 por ciento en 1960 a 56,4 por ciento en' 1964.

"Sornal do Brasil, 11 de Marzo de 1970. 
Tales regímenes no buscan tanto de tener el cambio - de hecho, con frecuencia lo promueven- como controlar sus consecuencias desde arriba. Al cambiar, evitan los cambios. Mi segunda proposición consiste en que Brasil ha permanecido adherido durante largo tiempo a ese modelo de modernización defensiva desde arriba - "hagamos la revolución antes que la haga el pueblo" parece ser el pensamiento de la élite- y hay buenas razonés, aunque especulativas, para creer que el contexto de un desarrollo retrasado y dependiente favorece este curso de acción. Fuera de identificar genéricamente este modelo con su prototipo bonapartista, sin embargo, he dicho bien poco acerca de cómo está constituido este "conjunto homogéneo, interdependiente y relativamente estable de instituciones y prácticas políticas".

En esta tarea, así como en muchas otras, los analistas de la política brasileña han encontrado muy útiles las formulaciones pioneras de Juan Linz. He aquí, en breve, el diseño que Linz hace de los rasgos 'característicos de este tipo de sistema político:

Los regímenes autoritarios constituyen sistemas políticos basados en un pluralismo limitado y no responsable; sin una ideología elaborada e influyente (pero con una mentalidad bien definida); sin movilización política intensiva o extensiva, excepto durante algunos momentos de su desarrollo; y en los cuales un líder (u ocasionalmente un grupo pequeño) ejerce el poder dentro de límites formalmente poco definidos, pero de hecho completamente predecibles. ${ }^{37}$

Aunque he vuelto a especificar y he colocado otros nombres a algunos de los componentes de esta descripción, he introducido referencias empíricas distintas de las que Linz probablemente habría usado, $y$ he agregado un nuevo rasgo principal al cuadro: el del proceso de emancipación del poder ejecutivo que considero como una especie de compendio de todos los rasgos precedentes, en general tiende a seguir la caracterización de Linz. Corresponde ahora formular ciertas preguntas. ¿Qué es lo que han hecho los gobernantes militares de Brasil desde 1964 para alterar el modelo autoritario del "Varguismo"? ¿De qué manera el comportamiento y los resultados de las políticas del régimen, discutidas más arriba, se relacionan con este esfuerzo encaminado a perfeccionar $y$, por consiguiente, institucionalizar una variedad nueva, más pura y más portuguesa de estilo autoritario?

${ }^{37}$ Obra citada, página 25\%. 
La regimentación de los grupos de interés, efectuada desde arriba, en un conjunto de categorías jerárquicas preestablecidas; la intervención y control oficial sobre sus asuntos financieros, la elección de sus dirigentes y la articulación de sus demandas; el monopolio formal de la representación de tales intereses; el establecimiento de una relación simbiótica entre estas asociaciones semivoluntarias y la burocracia central -en otras palabras, el corporativismo- es la "piedra angular del sistema"38 y un elemento clave del régimen autoritario en su conjunto. Los "revolucionarios" de 1964 lo reconocieron así rápidamente. A pesar de las protestas formuladas por elementos liberales dentro de sus filas, una de sus primeras "garantías" fue el mantenimiento de una legislación laboral consolidada y, específicamente, de la organización sindical que dicha legislación encerraba.

Claramente, uno de los signos de la decadencia del sistema anterior fue la creciente incapacidad del presidente y del ministro del trabajo para hacer cumplir las disposiciones restrictivas de esa legislación. Organizaciones parasindicales de trabajadores surgieron fuera del encuadramiento oficial; la elección de los dirigentes y la articulación de las demandas comenzaron a escaparse de sus manos; las relaciones de poder entre el ministerio y los sindicatos comenzaron a darse vuelta. Por parte de los empleadores, se formaron nuevas "entidades civiles" al lado de los sindicatos y antiguas asociaciones privadas fueron resucitadas; incluso los sindicatos y federaciones oficialmente reconocidos comenzaron a oponerse abiertamente al gobierno y a participar en actividades conspiratorias.

Sin cambiar una sola línea de la legislación vigente, pero aplicándola en la práctica en forma muy diferente los "revolucionarios" volvieron a hacer del movimiento sindical la piedra angular del sistema. Llevando a cabo amplias purgas, primeramente, y luego tomando el control del reclutamiento de dirigentes sindicales, obtuvieron la paz social impuesta que necesitaban para aplicar sus políticas restrictivas de salarios e inversiones. Por medios menos directos, expelieron de los sindicatos patronales a los "radicales" indeseables. Muchas de las enticlades civiles más militantes se eclipsaron o adhirieron a prácticas más obsecuentes. El otorgamiento

${ }^{38}$ La frase citada es de Oliveiros S. Ferreira. Para una discusión más extensa de este punto, ver mi Interest Conflict and Political Change in Brazil, especialmente páginas $383-386$. 





de subsidios y favores y su designación en una multitud de nuevos consejos consultivos fueron suficientes para incorporar al sistema al resto de los dirigentes.

Por consiguiente, el activo pluralismo institucional e ideológico de comienzos de los años 1960 fue suprimido en forma brusca y efectiva, y el sistema volvió a su anterior configuración unitaria, centralizada y corporativista. El cuadro VIII muestra algunas de las consecuencias de este proceso. El número total de sindicatos de trabajadores aumentó brevemente, entre 1965 y 1967, y luego declinó a los niveles anteriores. La clase trabajadora urbana fue encuadrada mientras que el número de afiliados a las organizaciones sindicales creció en forma puramente vegetativa. Lo mismo puede decirse en cuanto al número de sindicatos patronales, si bien en este caso la afiliación creció en forma significativa.

La prohibición casi completa de huelgas o incluso de medios menos agresivos de plantear las demandas de los sindicatos ha resultado en una notoria burocratización de las relaciones de clase, como lo demuestra el creciente flujo de casos presentados ante las Juntas de Conciliación y Juzgamiento, tribunales de menor cuantía en lo laboral.

De especial importancia, sin embargo, es el sector rural. Después de clausurar casi todos los sindicatos rurales y todas las ligas campesinas formadas bajo el gobierno de Goulart, los militares han procedido en forma gradual y continua a conceder legitimidad a las asociaciones formadas en el seno de ese sector escasamente representado. Es importante observar, con todo, que la tasa de formación de sindicatos de empleadores rurales ha sobrepasado con ventaja la de los sindicatos campesinos, en parte como resultado de la transformación puramente jurídica de las asociaciones rurales existentes en sindicatos propiamente dichos y en parte como consecuencia de una política deliberada del gobierno. Sin embargo, no hay razones para no esperar que dentro de un plazo relativamente corto cada municipio estará enmarcado dentro de esta red organizativa, oficialmente promovida, en torno a la cual se desarrollará en breve un conjunto mínimo de servicios sociales ${ }^{39}$. El remanente, el área no corporativizada, que produjo una gran ansiedad durante el gobierno de Goulart, se encontraría copado y, presumiblemente, colocado más allá del alcance de todo proceso radical de movilización política.

${ }^{39}$ Consultar el artículo Decréto ámplia a previdencia rural, en El Estado de San Paulo, Julio 24 de 1969. 
UN RÉGIMEN NO PARTIDISTA DE PARTIDO ÚNICO

Linz no incluye esta característica en la descripción sumaria anotada anteriormente si bien, del contexto de su extenso análisis, parece desprenderse que tal característica sería un importante componente estructural del sistema español maduro y, por extensión, del portugués. Un partido oficial debe ocupar formalmente una posición clominante, pero no monopoliza todo el acceso al poder. "Una parte considerable de la élite carece de conexiones con el partido y no se identifica con él. La afiliación partidista crea pocas ventajas visibles e impone pocas obligaciones, o ninguna" 40 . De hecho, uno podría argumentar que la función primordial de un partido en un régimen autoritario estable consiste en actuar tan poco como sea posible, ocupando el espacio reservado a los partidos dentro de un sistema político, a fin de prevenir la formación de organizaciones menos obsecuentes y más competitivas.

El Estado Novo constituyó una especie de curiosidad entre los regímenes autoritarios del período que medió entre las dos guerras mundiales, por su incapacidad para mantener siquiera la ficción de un sistema basado en un partido dominante. A la necesidad de "redemocratización" surgida en los años 1940, Vargas respondió ingeniosamente creando las bases para una coalición basada en dos partidos dominantes, que funcionó razonablemente bien, en su provecho, hasta 1960. La victoria de Janio Quadros y la ulterior transferencia, por un breve período, del control del aparato estatal a otra coalición, que aún no era institucionalmente dominante, ejerció severas presiones sobre el sistema. La proliferación del número de partidos, las xápidas alteraciones en la composición de fuerzas y los constantes cambios de las alianzas políticas en el período de Goulart fueron magnificados por la creciente ambigüedad en torno a las elecciones presidenciales de 1965. La ingeniosa fórmula varguista, que permitió la competencia a nivel local sobre la base de cambios en las coaliciones, pero que al mismo tiempo aseguró un dominio estable a nivel nacional, a través de la presidencia, se fue desintegrando mientras emergía un cuadro social e ideológicamente más polarizado, centrado en los frentes parlamentarios. El sistema había pasado de un estado semicompetitivo a una situación abiertamente competitiva.

Los golpistas de 1964 no entendieron en un comienzo las consecuencias de ello. El Acta Institucional No 1, y en forma aún más

^o Obra citada, página 264. 
explícita los discursos de los dirigentes revolucionarios, implicaban la continuación del sistema competitivo existente. Las elecciones relativamente libres de 1965 revelaron de inmediato el error de cálculo en que se había incurrido, por lo que fueron seguidas de un Acta Institucional No 2 que abolía todos los partidos existentes. A continuación, los militares se pusieron a la tarea de construir un sistema de partidos más apropiado a sus ambiciones políticas de largo plazo hasta arribar a un sistema basado en un partido y medio. El predominio del partido oficial (ARENA) sobre el de oposición, el Movimiento Democrático Brasileño (MDB), tenía que ser garantizado por el poder ejecutivo mediante la purga y manipulación periódica. Es interesante observar que, sin embargo, las nuevas autoridades continuaron con la práctica de permitir conflictos a nivel local, a través del expediente de subinscripciones o listas competitivas dentro del mismo partido, para las elecciones estaduales y municipales. En cambio, trataron de reducir la competencia a nivel nacional, insistiendo en una estricta disciplina particlista en las votaciones parlamentarias.

Aun esto pareció inadecuado para arrancar las raíces "perniciosas" de la' lucha partidaria. En un gesto de desafío -después de años de complaciente asentimiento a los diktat del ejecutivo- el partido de gobierno se dividió, en diciembre de 1968, por causa de una discusión acerca de la privación cle la inmunidad parlamentaria de uno de los diputados de la oposición, al cual se buscaba procesar por crímenes contra "el honor de las fuerzas armadas". La pronta respuesta fue el Acta Institucional $N$ \% 5, que clausuró el congreso e inauguró una nueva ola de actos represivos (cinco senadores y 88 diputados perdieron de inmediato sus derechos políticos), que continuó hasta 1970:1. Esta medida todavía se encuentra en vigor, aunque no ha sido invocada en forma activa por el gobierno de Médici.

A pesar de las sugerencias ocasionales formuladas por algunos militares a los efectos de establecer un partido único a la mexicana, organizado en forma más rígida - se ha mencionado el nombre de Partido Revolucionario Nacional- el sistema bipartidista anterior fue puesto nuevamente en servicio después de un prolongado receso. Este sistema sirvió para reclutar mayorías impresionantes, y aparentemente honestas, para los candidatos del régimen en las elecciones de noviembre de 1970, para el congreso y las legislaturas estaduales. Solamente una legislatura estadual (Guanabara) no es controlada por el ARENA, que dispone de una confortable mayoría de 222 ban-

"La traducción inglesa de estas y otras medidas, así como una traducción parcial de la Constitución de 1967, se puede encontrar en Bradford Burns, A History of Brazil, Nueva. York: University of Columbia Press, 1970, páginas 390-413. 
cas cointra 88 en la Cámara Federal ${ }^{42}$ y una mayoría de 38 a 6 bancas en el senado.

No obstante el hecho de que está resultando cada vez más difícil reclutar candidatos, especialmente para el MDB, y que los editoriales de los periódicos continúan vituperando la naturaleza "antinatural" de ambos partidos ${ }^{43}$, este sistema de partidos artificial y poco representativo resulta enteramente apropiado para un prolongado régimen autoritario. Iśl provee la fachada de instituciones democráticas y la oposición domesticada que dicho régimen precisa, sin imponer restricciones serias al poder ejecutivo. Las funciones esenciales del partido político - la agregación de intereses, la selección de candiclatos y el manejo de la renovación de los gobernanteshan sido usurpadas por los organismos de seguridad del poder ejecutivo. Los militares son el verdadero partido monopólico de Brasil.

\section{DESMOVILIZACIÓN Y APATÍA POLÍTICAS}

A diferencia de una democracia pluralista, donde se busca apoyo a través de una extensa participación voluntaria en asociaciones politicas autónomas, o de un régimen totalitario donde se promueve la devoción intensa y entusiasta a través de un frondoso conjunto de organizaciones dependientes del partido único o regidas por éste, un sistema autoritario estable "espera con frecuencia -incluso de los servidores públicos y civiles- la aceptación pasiva 0 , al menos, su abstención de toda actividad pública antigubernamental"'4. Como Linz señala adicionalmente, se trata de una característica acerca de Ia cual los casos empíricos muestran una amplia gama de variaciones, desde el elitismo burocrático de España y Portugal al populismo personalista de la Argentina de Perón o del Brasil de la posguerra. Sin embargo, hacia fines de los años 1950 y en los primeros años de la década siguiente, es probable que la movilización política en Brasil hubiera excedido los límites de la tolerancia del régi-

12Consultar el Jornal do Brasil, 21 de Diciembre de 1970, para una lista y descripción de los candidatos victoriosos. También $V E J A, 25$ de Noviembre de 1970, páginas 24-25. La formación de un tercer partido es escasamente probable, a pesar de las "amenazas" ocasionales de hacexlo. De acuerdo al sistema electoral actual requeriria 864.271 firmas de votantes registrados o cl cinco por ciento de esa votación en la última elección. Consultar el Jornal do Brasil, 28 de Marzo de 1970.

"Is"Los dos partidos que tenemos, escasamente consiguen promover el minimo de actividad política necesaria para mantener viva la ilusión de clemocracia". Quarto Menguante, Jornal do Brasil, 24 de Marzo de 1970.

"Juan Linz, "L'opposizione in un regime autoritario:: il caso della Spagna" en Storia Contemporanea, I, 1 (Mrarzo de 1970), páginas 63-102. 
men autoritario estable, especialmente en la medida en que el interés activo en la política parecía estar desbordando la capacidad de asimilación y cooptación de las instituciones estatales.

Muchas de las medidas tomadas por las autoridades "revolucionarias" ya han sido mencionaclas más arriba: purgas en los sindicatos; disolución de ligas campesinas y de otras organizaciones paralegales "subversivas"; privación de derechos políticos a dirigentes populares y populistas; postergación de elecciones; cuidadoso control de los militares sobre la selección de candidatos a todos los niveles; censura de los medios de comunicación en todo lo referente a la información política; destrucción del sistema anterior cle partidos y su sustitución por entidades artificiales sin raíces populares. Ciertamente, el principal cambio estructural consistió en el establecimiento de: elecciones indirectas para la presidencia de la república y todas las. gobernaciones estaduales, elecciones que pasaron a ser el resultado. de las deliberaciones de unos cuerpos legislativos previamente purgados y domesticados. Bajo tales condiciones, no existía ni la oportunidad $\mathrm{ni}$ la necesidad de movilizar apoyo popular o de apelar a clientelas electorales privadas de sus derechos. El reductio ad absurdum ocurrió en octubre de 1969 con la elección del reemplazante: para el ya achacoso Costa e Silva. El electorado consistió en un: "senadito" de 118 generales, 60 almirantes y 61 brigadieres (generales de la fuerza aérea) en consulta con una "cámara" de coroneles y con la eventual aprobación proformal del parlamento federal. Esto constituyó una decadencia completa en relación con los doce millones de electores que habian votado en la última elección presidencial.

Sin embargo, continuaron realizándose elecciones (regularmente y al capricho del ejecutivo) y el electorado pudo así tener alguna voz. Lo anterior no es insólito en un régimen autoritario. En Portugal las elecciones funcionan tan regularmente como un reloj. El cuadro IX indica que, hablando proporcionalmente, la población electoral ha cambiado muy poco desde fines de los años 1950, fluctuando entre 18 y $20 \%$ de la población total. Aunque el registro electoral casi se ha duplicado descle la campaña presidencial de 1960, el abstencionismo parece haber aumentado, a pesar de que el voto es obligatorio y se han establecido sanciones más duras. También ha aumentado, aparentemente, el porcentaje de votos en blanco y nulos. No pude disponer de las cifras exactas correspondientes a las elecciones parlamentarias de 1970, pero la revista Veja informó que el $50 \%$ de los ciudadanos inscritos no votaron, tomando en cuenta los votos nulos además de las abstenciones. En algunos estados, la proporción de votos nulos excedió el $35 \%$ y, aparentemente, fue 


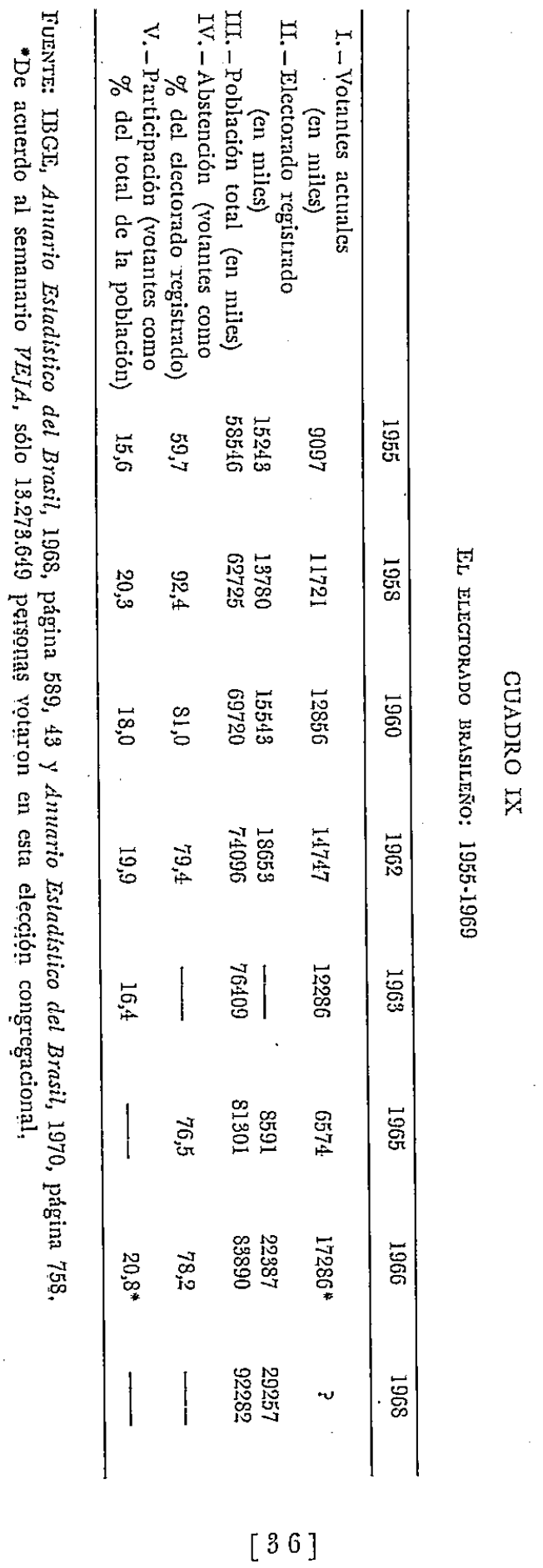


un factor que inciclió en los pobres resultados que alcanzó el MDB.45

Desgraciadamente, no se dispone de ninguna encuesta que permita medir hasta qué punto los brasileños simplemente han renunciado a toda tentativa de relacionar sus problemas, intereses y actitudes con el proceso político oficial, y se han refugiado en una zona de privacidad apática o bien se han resignado a utilizar canales puramente burocráticos \pm 0 . Recientes investigaciones (que hay que reconocer no inspiran mucha confianza) sobre las actitudes de los jóvenes -especialmente de aquellos que tienen pocos recuerdos o experiencia de un proceso político más abierto y competitivo, como ocurre con los que votan por primera vez- sugiere que la despolitización Ios ha afectado. Frente a la pregunta "¿por qué vota usted?", el $55 \%$ replicaron simplemente "por obligación" y otro $28 \%$ dijo "para cumplir un deber". Sólo el $10 \%$ pensaba estar ejerciendo un derecho y el $4 \%$ lo estaba haciendo, "por interés en el futuro del país". Pruebas cualitativas revelaron un profundo sentido de alejamiento con respecto a los políticos como tales y bajos niveles de información política. "Aun cuando se quejan de los hombres públicos y tienden a generalizar en sus acusaciones, los jóvenes no demuestran ni siquiera un conocimiento razonable de la actividad política o una posición consciente contra el régimen que permite la subsistencia de tales personajes". Solamente unos pocos (6\%) estaban en favor de votar en blanco (porcentaje que aumentó al $11 \%$ en São Paulo), y sus preferencias partidistas eran similares a las de los adultos (si bien no mostraban entusiasmo por los partidos como tales). ${ }^{47}$

Tanto la información general como los resultados de la encuesta son incompletos pero concordantes. Cualesquiera que hayan sido las tendencias que hayan emergido a comienzos de los años 1960 hacia una mayor participación política - hacia la transferencia de aspiraciones e intereses desde canales privados o burocráticos hacia otros más públicos y competitivos, hacia una creciente confianza en la autenticidad y representatividad cle los políticos- seis años de régimen militar las han invertido. La quinta parte de la población que, aproximadamente, vota en las elecciones o participa en sindicatos lo hace a causa de un vago senticlo del deber, por temor a sanciones

${ }^{4}$ V Veja, 25 de Noviembre de 1970.

46"Esta preocupación con el procedimiento... puede prevenir que los problemas políticos sean percibidos como tales, irreductibles a los problemas administrativos, y no ser absorbidos por la legislación. Los procedimientos legales son vistos a menudo ... como un equivalente adecuado de una expresión más colectiva y más politica de los conflictos de interés", en Juan Linz, An Authoritarian Regime: Spain, página 273.

${ }_{17 " A}$ jovener maioria silenciosa", Veja, 18 de Noviembre de 1970, páginas 20-25. 
$\because$ ESTUDTOS INTERNACIONALES

'o por falta de alternativas pero, en todo caso, con un espíritu profundamente cínico, con poco respeto por la caliclad de sus dirigentes y una completa falta de entusiasmo.

\section{EL, ROL DE LAS MENTALIDADES}

En mis trabajos anteriores, argumenté extensamente que el sistema varguista dependió de las características de la cultura política brasileña y se desarrolló a partir de ellas. Esa predisposición hacia una pauta de solución de conflictos consensual y negociada (actualismo), -basada en el pragmatismo, la tolerancia y la clilación, en la limitación deliberada de los objetivos, en arreglos parajurídicos (jeitos) $\mathrm{y}$ en formalismos legales (bacharclismo), tenían sus raíces en las prácticas republicanas anteriores, pero alcanzaron su pleno florecimiento bajo la "dictablanda" posterior a 1930. También he dis:cutido la desintegración de esas reglas operativas después de 1960: -la pertinaz intransigencia en el interior de las élites, la impaciencia popular, el inmovilismo decisorio, el formalismo demagógico, la rigidez :ideológica y la polarización política. Puede haber sido un tanto prematuro el anuncio de que los "hombres cordiales" habían sido descartadios y reemplazados por un grupo de "hombres radicales", más agresivos $\mathrm{y} \cdot \mathrm{con}$ una mayor conciencia de clase $^{48}$, pero en todo caso: se estaba produciendọ una profunda transformación en la cultura política brasileña.

También resultaba claro que los nuevos gobernantes militares del Brasil tenían la intención cle detener ese proceso. Sus primeros actos fueron esencialmente negativos: persecución de los ideólogos radicales más prominentes, clausura de instituciones "subversivas" de indoctrinación de dirigentes tales como el Instituto Superior de Estudios Brasileños (ISEB) ${ }^{49}$, despolitización de programas de alfabetización de masas tales como el Movimiento de Educación de Base (BED) ${ }^{50}$, y la aplicación de censura a los medios de comunicación, si bien en forma difusa y un tanto errática.

Sin embargo, una respuesta más positiva comenzó a emerger gradualmente. Durante años, las asociaciones de mujeres y las sociedades

${ }^{48}$ Consultar a Pessoa de Morais, Sociologia da Revolução Brasileira, Río de Janeiro, Editora Leitura, 1965.

${ }^{10}$ Frank Bonilla, A National Xd'eology for Development: Brazil, en K. Silvert (editor), Expentant Peoples. Nueva York, Random House, 1963, páginas 232-264.

${ }^{50}$ Emanuel de Kadt, Catholic Radicals in Brazil, Londres y Nueva York, Oxford University Press, 1970, especialmente páginas 190-211. Recientemente, se informó que MEB habia clejado de existir. Consultar el Times of the Americas, 21 de Abril cle 1971. 
patrióticas de orientación conservadora, tales como la Liga de Defensa Nacional, se habían quejado de que los ciudadanos brasileños no recibían una "educación cívica y moral" adecuada. A falta de un proceso de indoctrinación basado en los valores representados por el orden, la obediencia, la responsabilidad, el respeto por las jerarquías, el patriotismo, la familia, la comunidad y la solidaridad -argumentaban- los inocentes jóvenes tenían que caer en la tentación de abrazar "ideologías foráneas" que acentuaban los valores contrarios. Durante la década de 1960 muchas de esas organizaciones comenzaron a desarrollar programas de "educación cívica y moral" por su propia cuenta ${ }^{51}$, pero con recursos y efectos limitados.

Ya en 1966 los militares comenzaron a expresar su interés por convertir esas iniciativas privadas en un programa público debidamente concertado. Sin embargo, aparte de algunas declaraciones verbales de estímulo y unas cuantas conferencias, esa idea no fue aplicada. Finalmente; el 19 de setiembre de 1969, sin fanfarrias y en el medio de la crisis en torno a la sucesión de Costa e Silva, se promulgó el decretoley 869-69. Ese decreto establecía un amplio programa de Educación Cívica y Moral en todos los niveles del sistema educativo, supervisado por una Comisión Nacional de Moralidad y Civilismo (CMMC). El decreto tampoco dejaba duda alguna acerca del contenido ideológico de la enseñanza que se impartiría en los centros cívicos escolares (educación primaria y media) y en los centros cívicos súperiores (a nivel universitario), ya que describía detalladamente sus propósitos: "Defensa de la idea democrática (sic), a través de la defensa del espíritu religioso, la dignidad de la persona humana y el amor a la libertad con responsabilidad, bajo la inspiración de Dios... el fortalecimiento del carácter, basado en la moralidad, a través de la dedicación a la comunidad y a la familia... la honra de la patria y de sus símbolos, tradiciones e instituciones... la capacitación de los ciucladanos para desarrollar actividades cívicas, inspiradas en la moralidad, el patriotismo y la acción constructiva para el bien común"'. Para asegurar la anuencia de los ejecutores del programa, los profesores debían suscribir una declaración escrita testimoniando su conformidad con las bases filosóficas del decreto. Incluso se sugirió la posibilidad de incorporar, como profesores visitantes, a oficiales del ejército en caso cle que no hubiera profesores civiles disponibles. Un Plan de Emergencia fue redactado inmediatamente y;

"Consultar a Norman Blume, Pressure Groups and Decision Making in Brazil en Studies in Comparative International Development, III, 11 (1967-68), para detalles sobre una asociación activa (IPES) en esta área.

"Consultar a Hugo Assman, "Cuando Dios es utilizado para legitimar la Dictadura". El original apareció en Perspectivas de Diálogo, Montevideo, Agosto de 1970 . 
hasta donde yo sé, todos los estudiantes brasileños, públicos y privados, comenzaron a recibir ese tipo de educación política y religiosa durante dos horas la semana desde el segundo semestre de 1970.

Aunque aparentemente no hay sobreposición con el programa anterior, el régimen comenzó de una manera vacilante, en diciembre de 1967, y en forma masiva a partir de setiembre de 1970, a alfabetizar la población brasileña. Una gigantesca campaña, generosamente financiada, al estilo militar (el Movimiento Brasileño de Alfabetización, MOBRAL) fue puesta en marcha con la intención de incorporar a dos millones de analfabetos en 1971 y a cinco millones hacia $1973^{53}$. La campaña se inició en las áreas urbanas del sur, según lo aconsejaba la prudencia, pero proyectaba extenderse con el objeto de cubrir las regiones prioritarias señaladas por el Ministerio del Interior, trabajando a través de autoridades locales especialmente designadas. Se solicitó la cooperación de las empresas privadas y se estimuló el otorgamiento de donaciones a través de incentivos fiscales. No hay pruebas de que este esfuerzo haya ido acompañado de un contenido político manifiesto (como ocurrió claramente durante las campañas de alfabetización del período de Goulart), pero el propósito político latente es bastante obvio: "Alfabeticemos a esta gente y despertemos su agradecimiento, antes que lo hagan los elementos subversivos". Sin embargo, MOBRAL representa uno de los riesgos calculados de un régimen que, en general, ha demostrado ser cauteloso. Como lo observó el director de esta campaña, Mario Simonsen, "la alfabetización crea nuevas necesidades en los individuos, expandiendo los estímulos y los horizontes de sus ambiciones vitales"54. De qué manera un sistema político basado en la reducción deliberada de los estímulos y horizontes políticos pueden satisfacer esa necesidad, constituye una pregunta desafiante.

Para asegurar que los nuevos alfabetos no puedan ver o escuchar ninguna experiencia intoxicante, la censura se ha puesto cada vez más estricta y sistemática. De acuerdo con las "normas doctrinarias" del Servicio Federal de Censura, solamente los programas y publicaciones que "despiertan las responsabilidades civiles; combaten el egoísmo, la rebelión y la desobediencia; exaltan la lealtad, el heroísmo y el cumplimiento del deber, o estimulan el respeto por los mayores y el amor a la patria y a los acontecimientos históricos" son permitidos ${ }^{55}$. ¡Si en el futuro sólo se podrán leer estas ñañerías, el analfabetismo no sería una mala idea!

¿3"A Derrota da Ignorância", Veja, 9 de Setiembre de 1970, páginas 40-46. También, Jornal do Brasil, 28 de Diciembre de 1970, que informó que medio millón habia sido empadronado en ese período.

"Veja, 9 de Setiembre de 1970, página 43.

"s"O Código do corte", Veja, 9 de Setiembre de 1970, página 24. 
La culminación de las tentativas del régimen para apoyarse en una firme mentalidad conformista radica en su extraordinaria manipulación de los símbolos patrióticos y chauvinistas. Al capitalizar el triunfo deportivo en la Copa Mundial Jules Rimet, el estado inundó el país con banderas, himnos, paradas, canciones, carteles y panfletos que exaltaban la grandeza del Brasil. El punto culminante coincidió con el día de la independencia del Brasil, el 7 de setiembre de 1970 , cuando un equipo especial de asesores presidenciales planearon una verdadera orgía de una semana de duración de acontecimientos patrióticos (solamente en Río de Janeiro se realizaron 545 "solemnidades"). Existen indicaciones de que los brasileños, tradicionalmente muy poco dados a tales expresiones de ufanismo (pequeñas expresiones de patriotismo chauvinista con banderas clesplegadas), gozaron del espectáculo, y de que el régimen se propone alimentar generosamente tales acontecimientos circenses en el futuro ${ }^{50}$.

La mayor parte de los informes generales sobre el Brasil, desde 1964, han enfatizado los dramáticos cambios ideológicos al nivel de la dirigencia del país. Dichos informes han enfatizado, en particular, el papel preponderante de un conjunto peculiar de valores, conocido como la Doctrina de la Seguridad Nacional, elaborada por una camarilla de intelectuales de las fuerzas armadas, la Escuela Superior de Guerra (ESG). He preferido enfatizar las tentativas dirigidas a la indoctrinación de las masas en la medida en que veo en ellas el elemento crucial de la portugalización del Brasil, a lo menos en el largo plazo. En todo caso, numerosas interpretaciones de la doctrina de la ESG han aparecido por todas partes.

Al respecto, sólo quisiera hacer unas cuantas observaciones de carácter general. A pesar de que su contenido sustantivo es indudablemente autoritario -especialmente en la medida en que asigna al estado un papel hegemónico exclusivo en la identificación y promoción de los objetivos nacionales - la doctrina mencionada bien podría ser antitética a un régimen autoritario estable. Ante todo, resulta demasiado rígida al fijar las metas del sistema y, por lo tanto, podría resultar incompatible con las notas perseguidas por los grupos económicos, religiosos y sociales cuyos intereses busca proteger. Por lo demás, es demasiado exclusivista y puritana, al reservar a los militares. la plena responsabilidad por la adopción de las decisiones, lo que podría frustrar las aspiraciones de los demás grupos hacia una mayor movilidad y participación políticas. Resulta también muy difusa en su definición de los opositores a la seguridad nacional, lo cual podría limitar la capacidad del régimen para reclutar sus dirigentes y para

so" O Dia do Brasil", Veja, 9 de Setiembre de 1970, páginas 16-19. Tambièn: "O növo ufanismo", Realidade, Setiembre de 1970, páginas 98-105. 
'cambiar sus bases de apoyo frente-a circunstancias cambiantes. Por último, resulta demasiado estrecha en cuanto fundamenta la legitimidad del régimen en un sólo criterio: la defensa del Brasil contra -el comunismo ateo. La erradicación represiva de toda resistencia interna y/o la consecución detente mundial entre las grandes potencias, podría eliminar la plausibilidad de una justificación como esa. Las predicciones formuladas más arriba se basan en la presunción de que la Doctrina de la Seguridad Nacional es tan elaborada, rígida, comprensiva y mandatoria como parece serlo, y no solamente una fachada útil para racionalizar ex post cualquier expediente que los militares deseen seguir ${ }^{57}$. En último término, se trataría de una mentalidad elitista apropiada para la institucionalización del régimen autoritario - y un valioso complemento de sus esfuerzos para indoctrinar a las masas en el plano de la cultura política.

\section{CONSTITUGIONALIZAGIÓN}

Los regímenes autoritarios estables no son ni arbitrarios ni caprichosos. Ningún sistema político puede persistir sin un mínimo de institucionalización de sus procesos de adopción de decisiones, pero la naturaleza de los reglamentos procesales y el grado de autolimitación del sistema puede variar de acuerdo con el tipo de regímenes. Los democráticos, logran bastante en tal sentido mediante una yuxtaposición de poderes funcionales y territoriales; los totalitarios, consiguen peores resultados a través de un sistema paralelo de organizaciones particlistas y estatales interrelacionadas. Los regímenes autoritarios buscan, en forma característica, el establecimiento de un equilibrio centralmente manipulado entre jerarquías institucionales aproximadamente iguales. Cada una de esas corporaciones - siendo las más clásicas las de los militares, el servicio civil, la iglesia, los negocios $\mathrm{y}$, tal vez, las burocracias partidistas- recibe un grado sustancial de autonomía dentro de su esfera política respectiva (segmentación política). El control centralizado es asegurado y mantenido a través 'de la cuidadosa actividad compensadora de un soberano "neutral",

"Mientras la Doctrina puede continuar conservando como reliquias las metas primarias y la sabiduría del tutelaje militar en los niveles más altos de abstracción, hay indicaciones de que la Escuela Superior de Guerra puede ser desyiada a tareas más concretas. En el discurso a la ESG, Médici sugirió que él deseaba "que se preocuparan menos con conceptualismos teóricos... y se empeñaran más en la elaboración de proyectos objetivos y reales". Esta conversión en "una verdadera escuela de estadistas" (sic) sería mucho más compatible con la mentalidad prevalente de un sólido sistema autoritario. Consultar el Jornal do Brasil, 1 il de Marzo de 1970. 
'que resuelve las disputas emergentes entre las corporaciones. Idealmente, él o ellos (el régimen de junta no es en modo alguno desusado) sólo tendrán que intervenir de vez en cuando y normalmente podrán descansar en el control jerárquico, basado en los pilares corporativos debidamente subordinados. Sólo en momentos de crisis, se ven obligados a afirmar su primacía. In la variante populista, los dirigentes deben hacerse visibles por si mismos, en virtud de un "pacto directo con las masas", pero en la variedad portuguesa más tradicionalista y más estable, el poder ejecutivo llega a ser prácticacamente invisible pero también completamente predecible. Ese alojamiento de la lucha política diaria resulta útil. Permite a los líderes asignar a sus subordinados la responsabilidad por los errores cometidos, economizar recursos para emplearlos en situaciones críticas, y les permite cambiar las bases de las coaliciones que los apoyan con la mayor impunidad.

Los gobernantes militares del Brasil no han sido capaces hasta ahora de constitucionalizar sus procedimientos de ésta o de otra manera. No han encontrado ninguna fórmula especial para darle estabilidad institucional al régimen que pueda exonerarlos de responsabilidad por los resultados de sus decisiones, suministrarles un mayor margen de maniobra en el manejo de las coaliciones, y reducir los costos generales del terror y la represión a través de una mayor confianza en el acatamiento voluntario a las imposiciones del sistema. Carente de legitimidad y predictabilidad, el régimen exagera la magnitud de las amenazas a su persistencia y reacciona en forma exagerada frente a las situaciones criticas. A su vez, esto torna más difícil su constitucionalización futura.

Especulativamente, yo sugeriría que la institucionalización de un régimen autoritario debe ser precedido de dos importantes cambios políticos. Una intensa concentración de los recursos decisorios en el centro y una extensa penetración de las agencias gubernamentales en la periferia. Desde 1964, Brasil ha avanzado un largo trecho hacia esos dos prerrequisitos.

La centralización en Brasil, después del golpe, ha alcanzado niveles sin precedentes a través de la subordinación gradual, pero sistemática, de todos los poderes compensatorios, ya sea funcionales o territoriales. $\mathrm{E} 1$ cuadro $\mathrm{X}$ muestra que, en términos de cantidades reunidas o dispersas, la proporción de autoridades federales, estaduales y municipales sólo se ha modificado ligeramente. Lo que el cuadro no muestra, es que todo el esquema impositivo ha cambiado en favor del gobierno federal, el cual gracias a ello subsidia las operaciones de los gobiernos estaduales y municipales y, por ello mismo, 


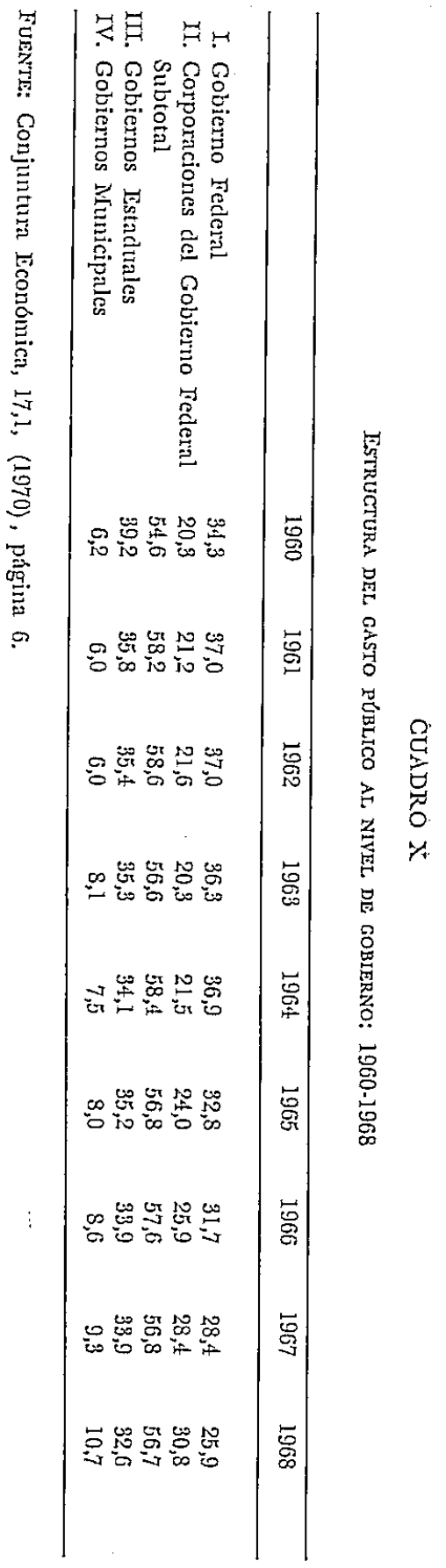

[44] 
las controla ${ }^{58}$. La nueva constitución de 1967 impide que las autoridades locales persigan políticas incompatibles con el gobierno federal, les exige rendir cuentas detalladas de todos sus gastos y extiende apreciablemente el área de la intervención federal. Dicha intervención ha sido usada con frecuencia para llevar a çabo purgas en los dos niveles locales anteriormente mencionados, por distintos motivos. Las funciones policiales han siclo transferidas casi completamente a los ministerios militares, los que ahora controlan todas las secretarías de seguridad y las milicias al nivel de los estados. Las actividades de otras secretarías estaduales han sido coordinadas a través de visitas obligatorias a Río o Brasilia Si estos medios de control son vinculados a la estrecha supervisión ejercida por el presidente de la república sobre la nominación de las autoridades y candidatos de los partidos -especialmente a nivel estadual-59 resulta difícil imaginar qué clase de autonomía gozan esas instituciones políticas descentralizadas. Los que otrora fueron estados poderosos han sido reducidos a unidades administrativas convenientes para las autoridades centrales y los municipios han sido convertidos en dependencias fácilmente manejadas. ${ }^{60}$

Tampoco les ha ido mejor a los poderes compensatorios funcionales. El Congreso Nacional, como hemos visto, ha sido purgado reiteradamente y simplemente clausurado por la fuerza (como ha ocurrido con las asambleas estaduales). Bajo la constitución de 1967, extensa y restrictivamente reformada en 1969, los diputados dejaron de gozar de inmunidad legal frente a los tribunales, sólo pueden pertenecer a un número limitado de comisiones investigadoras (nin-

${ }^{58} \mathrm{~A}$ fines de 1960, estas provisiones de participación en los impuestos fueron cambiadas, reduciendo las cuotas pagaderas a los municipios y estados del Fondo de Participación en un cincuenta por ciento. Este dramático corte en las rentas fue ligeramente mitigada por la creación de un Fondo Especial (dos por ciento) el cual, sin embargo, será asignado de acuerdo con el juicio político de las autoridades centrales.

${ }^{58}$ Consultar a Joseph Novitski, Brazilian President Names Gubernatorial Can.didates. New York Tímes, 9 de Julio de 1970. Novitski observa que los veintidós candidatos seleccionados eran conservadores, sometidos al gobierno de Brasil, $y$ dispuestos a usar las técnicas de planificación en el gobierno. Nueve de los futuros gobernadores eran tecnócratas que no habian sido activos en política.

${ }^{60 "} \mathrm{El}$ nivel municipal es esencialmente un sistema cautivo... El papel de las municipalidades es poner en ejecución los planes nacionales de desarrollo postrevolucionarios y, por supuesto, su real sobrevivencia ahora depende de la actitud, planes y objetivos de la rama ejecutiva del Gobierno Federal. Al manipular los porcentajes de los ingresos federales compartidos con las municipalidades, $y$ los mecanismos de control fiscal, el gobierno federal no es otra cosa que un titiritero que mueve aproximadamente 4.000 municipalidades". Ivan L. Richardson, Municipal Government in Brazil: The Financial Dimension, en Journal of Comparative Administration, vol. I, Ne 3 (Noviembre de 1969), página 339. 
guna de las cuales puede recibir financiamiento fuera de Brasilia);. y pueden ser expulsados por practicar "actos de infidelidad parti-. dista", como por ejemplo votar o intervenir contra la línea del partido o por faltar a una tercera parte de las sesiones. Ellos deben "apreciar" las proposiciones y los vetos del ejecutivo, de acuerdo con un procedimiento breve especial de 45 días, pasado el cual esas. iniciativas se convierten automáticamente en ley. Tampoco pueden proponer ninguna enmienda que envuelva nuevos gastos o establezca nuevas posiciones administrativas o modifique sus remuneraciones. Hay una larga lista de temas en los cuales el presidente tiene. la iniciativa exclusiva en materia de legislación ${ }^{61}$. Bajo tales condiciones, no resulta sorprendente que el congreso haya aprobado el presupuesto presentado por el ejecutivo en media hora, después de haber presentado diez mil proyectos de enmienda que fueron rechazados. ${ }^{62}$

Tampoco les ha ido mejor a los tribunales. Estos han sido purgados, ampliados, circunvalados y directamente intimidados hasta el punto de no ofrecer resistencia a las acciones manifiestamente extraconstitucionales del poder ejecutivo. En todo caso, el conocimiento de prácticamente la totalidad de los asuntos políticos ha sido transferido a tribunales militares especiales, pero incluso el papel de éstos se ha visto reducido a colocar un sello de legitimidad sobre las continuas acciones represivas del gobierno. ${ }^{03}$

Otra posible fuente de resistencia funcional a la, centralización administrativa puede haber sido, irónicamente, la propia burocracia federal ${ }^{64}$. Hipertrofiada, difícilmente manejable, reclutada en forma nepotista, dependiente de su clientela e internamente competitiva, ésta presentaba un serio obstáculo a la implantación del programa de austeridad de los militares victoriosos y a la consolidación de su hegemonía sobre el sistema político del país. Después de purgar a numerosos funcionarios, los militares iniciaron un programa sistemático de reforma administrativa, especialmente después de 1967. Pero más importante que sus esfuerzos encaminados a racionalizar la administración pública ha sido su extensa penetración por oficiales de las fuerzas armadas. En la actualidad, éstos pueden ser visualizados en casi todos los sectores del gobierno federal y estadual, ocupando cargos de importancia moderada. Una reciente encuesta que

-1"Novos Límites do Congreso", Veja, 22 de Octubre de 1969, páginas 16-19. "Meia Hora", Veja, 7 de Octubre de 1970, página 23.

${ }^{63}$ Consultar a Fenry J. Steiner y David M. Trubek, Brazil: All Power to the Generals, en Foreign Affairs, vol 49, No 3 (Abril de 1971), páginas 464-479.

- Para un análisis fascinante de la resistencia administrativa al régimen autoritario radical del nazismo alemán, ver Edward N. Peterson, The limit of Hitler's Power. Princeton, Nueva Jersey, Princeton University Press, 1969. 
abarcó 60 posiciones claves de la administración nacional, mostró. que 28 de ellas estaban ocupadas por oficiales de alta jerarquia. Algunos gobiernos estacluales han sido virtualmente militarizados ${ }^{65}$. Lo importante no es tanto su identidad y formación profesional, sino. el hecho de que ellos han sido escogidos directamente por la jerarquía militar y dentro de sus filas, de que permanecen dentro de las fuerzas armadas desde el punto de vista de su carrera, y de queperiódicamente vuelven a asumir posiciones con mando de tropa. En breve, la pauta anterior en virtud de la cual los oficiales eran: transferidos al estado civil mediante su prolongada dedicación al servicio público, ha sido conscientemente revertida.

Junto con esas tendencias centralizadas, se ha producido una enorme expansión en la capacidad del gobierno para penetrar la periferia del sistema político. La innovación más importante en tal sentido ha sido la creación de un Servicio Nacional de Información (SNI) tan extenso como bien organizado. Dirigido por un general con rango de ministro (el actual presidente es el ex jefe clel SNI), esteservicio interviene en prácticamente todos los aspectos de la vida política brasileña, a través de una variedad de medios que envuelven desde la investigación personal de todos los candidatos a ingresar en la administración pública y en las legislaturas hasta la conducción de encuestas masivas de opinión pública. Más de 200 oficiales en servicio activo trabajan en el SNI y son transferidos regularmente a otros puestos civiles y administrativos. Un artículo publicado recientemente en una revista hacía notar, en forma festiva, que: el $98 \%$ de las denuncias que llegan al servicio provienen de "informantes voluntarios que no reciben remuneración", y concluye que, mientras otras agencias comparables tales como el CIA y el KGB. consideran óptimo que el $20 \%$ de sus sugerencias sean aceptadas por el poder ejecutivo, el SNI ha obtenido la aprobación de más del $80 \%$ de sus recomendaciones por parte del gobierno ${ }^{60}$. Sus actividades son duplicadas, triplicadas y cuadruplicadas por otras agencias de espionaje dirigidas por cada una de las ramas militares, así como por los equivalentes civiles del FBI, el infame Departamento de Orden Político y Social (DOPS). El resultado ha sido la creación de una vasta red de recolección de información, que utiliza tanto las más modernas técnicas de procesamiento y almacenación de datos como los métodos más medioevales de extracción de los mismos, que

\footnotetext{
os"Os Militares", Veja, 18 de Abril de 1970, página 21. Por ejemplo, el Estado de Ceará tenia 35 oficiales en "puestos de comando" en su gobierno.

"os"Um Ministério Invisivel", Veja, 15 de Octubre de 1969, página 24.
} 
penetra en todas las instituciones privadas y en todos los niveles del gobierno. ${ }^{67}$

A otro nivel, existen importantes razones para sospechar que las autoridades centrales puedan estar estableciendo importantes vinculaciones directas con funcionarios municipales complacientes, sobrepasando y rebajando de categoría a las autoridades estaduales, las que irónicamente les suministraron las bases políticas para su rebelión contra el régimen de Goulart. Una reciente monografía sobre un municipio supuestamente representativo en el estado de São Paulo detalla cómo la "revolución" condujo a un mayor acceso de los clirigentes locales al poder y a una erradicación de las prácticas populistas y competitivas preexistentes en los mecanismos locales ${ }^{68}$. Combinando una extrema concentración del poder en el centro con el control local a través de oligarquías seleccionadas en la periferia, y vinculando ambos elementos dentro de una misma estructura de dominación militar y un sistema de inteligencia omnicomprensivo, los autócratas militares del Brasil podrían ser capaces de construir aquel sistema de dominación autoritaria estable que $\mathrm{Na}$ poleón III implantó a través del sistema policial y de las prefecturas. ${ }^{69}$

Aun cuanclo se cumplan esos dos prerrequisitos hipotéticos para la constitucionalización del régimen autoritario, el sistema de decisiones continúa siendo errático y caprichoso. Los que actúan en un plano subordinado no saben dónde se originan las decisiones, cómo se elaboran o cuáles son los límites de las demandas permisibles. Los elementos predominantes enfrentan pocas fuerzas compensatorias $y$, sin embargo, parecen inseguros acerca de su legitimidad $y$ de su subsistencia en el poder. La constitución de 1967 fue revisada antes de aplicarse y los militares se han opuesto a derogar el Acta Institucional No 5 , que les permite prescindir arbitrariamente de la endeble estructura legal que ellos mismos eligieron.

¿Por qué no fueron capaces de suministrar un mínimo de predictabilidad y de legalidad al régimen? $\mathrm{Si}$ aceptamos el viejo adagio, de que sólo el poder puede frenar al poder, entonces la primera

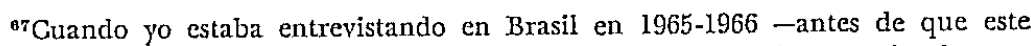
aparato hubiera sido elaborado por completo- varios de mis entrevistados me informaron espontáneamente que por sentido de deber patriótico ellos dieron cuenta al SNI de las deliberaciones internas de sus respectivas asociaciones. Muchos de éstos eran asimismo graduados de la Escuela Superior de Guerra (ESG) y activos en sus asociaciones de graduados (ADESG).

${ }^{88}$ Consultar a Fanny Tabak, "Desenvolvimento econömico sem desenvolvimento político na espera do poder local", documento presentado en la Mesa Redonda de IPSA, Río de Janeiro, 27-31 de Octubre de 1969.

${ }^{\circ}$ Como evidencia de una nueva reconciliación entre las autoridades seglares y sagradas, basada en la posterior "política propia", se puede consultar un documento que será publicado próximamente por Ralph della Cave. 
razón resulta obvia. El propio éxito alcanzado por los militares en su monopolio del poder eliminó todos los cuerpos opositores potenciales. Los grupos empresariales, internamente divididos, regimentados dentro de instituciones corporativas escasamente representativas, y dependiente de los créditos y concesiones del estado, no estaban en condiciones de compartir el poder. La burocracia civil, por las razones sugeridas más arriba, tampoco estaba en condiciones de defender los fundamentos tradicionales del poder, de tipo jurídico y racional, frente a la usurpación de los militares. La iglesia, una corporación aliada con frecuencia a los regímenes autoritarios tradicionales, había sido siempre institucionalmente débil en Brasil. Aun así, fue una facción de ella la que opuso una resistencia más fuerte al régimen arbitrario ${ }^{70}$. Las estructuras partidistas resultaron totalmente incapaces de oponer cualquier resistencia concertada al régimen, y fueron disueltas sin lamentos ni quejas. A falta de pilares corporativos y jerárquicos, de carácter competitivo, sobre los cuaIes construir el nuevo sistema, la portugalización resulta muy difícil, sino imposible La mexicanización -la creación deliberada de un aparato partidista designado de novo para competir con el establecimiento militar $y$, eventualmente, para reducirlo a un status subordinado- podría ser un camino posible hacia el orden constitucional, pero un camino que dependería de la emergencia de un estadista carismático en el seno de los militares. En segundo lugar, ninguna forma de constitucionalización que descanse en algún tipo de poder compensador - lo que parece ser de la esencia de esta fórmula- podría admitir la cuestión de la amnistía. Los dirigentes de los pilares corporativos, perseguidos y purgados por el régimen, tendrían que ser admitidos nuevamente en el sistema para llegar a algún grado de consenso específico. Gualquier movimiento en esta dirección despertaría de inmediato el espectro del revanchismo, esto es, de una competencia caótica entre los que retornaran y aquellos que habian usurpado sus privilegios y sus posiciones. Habiendo excedido con exceso los límites de la civilidad durante los regimenes anteriores (incluyendo el Estado Novo de corte fascista), los militares y la policía tenían buenas razones para temer las sorpresas que acarrearía inevitablemente una amnistía. La última y, quizá, la más obvia barrera a la normalidad radica en que mucha gente en el Brasil, incluyendo a los militares brasileños, sigue creyendo en la democracia pluralista y competitiva. Un régimen abiertamente autoritario, especialmente en su versión fascista, ya no podría descan-

70"O Presidente e a democracia", en Jornal do.Brasil, 11 de Marzo de 1970. Esta cita es una repetición directa de una conferencia de prensa del Presidente Médici, el 27 de Febrero de 1970. 
sar en el apoyo popular ni en la legitimidad de una moderna ideología, como ocurrió durante la década de 1930, y una desviación manifiesta y permanente de los símbolos de la democracia liberal probablemente podría exacerbar las tendencias facciosas dentro de los grupos militares, así como la resistencia al régimen de parte de algunos elementos burgueses y de los intelectuales.

Finalmente, han habido señales reiteradas de que el régimen intenta rectificar esa infortunada herencia histórica. Informantes gubernamentales han declarado oficialmente que el liberalismo o la democracia liberal es cosa del pasado o que, en todo caso, "la democracia real es un ideal que, si alguna vez fue realizado en alguna parte, ciertamente no lo fue en Brasil"'71. Ellos intuyen que la respuesta yace en un "estaclo revolucionario" nuevo, auténticamente brasileño, que garantizaría los derechos sociales antes que los individuales y que introduciría un "nuevo estilo democrático encaminado a la integración de todos en los esfuerzos del gobierno hacia el cumplimiento de objetivos sociales"72. Hasta aqui, no han habido indicaciones claras acerca de qué novedades institucionales posee el sistema o cuándo ellas serán promovidas. Sólo se cuenta con la promesa de que "el estado revolucionario se mantendrá durante el tiempo indispensable para la implantación de las estructuras políticas, administrativas, jurídicas, sociales y económicas capaces de promover la integración de todos los brasileños en un nivel mínimo de bienestar"73. El diseño de una fórmula que no sea abiertamente

${ }^{71}$ Jornal do Brasil, 18 de Abril de 1970. Las citas anotadias son de un discurso del Presidente Médici en la sesión de apertura del Congreso. Según las palabras ominosas del Ministro de Justicia, "el objetivo de la Revolución, al disciplinar la libertad individual, no es de limitar sus usos legítimos, sino sólo de organizarla de acuerdo con las necesidades de la seguridad nacional." Jornal do Brasil, 2 de Abril de 1970. El también habló de un "estado de justicia" en reemplazo del anterior "estado de derecho". Para una discusión interesante de cómo han emergido estos nuevos temas ideológicos, ver "Una Democracia", Veja, 8 de Abril de 1970, páginas 18-25. También, "O coquetel da reforma", Veja, 3 de Diciembre de 1970, páginas 17-19.

"Jornal do Brasil, Il de Marzo de 1970. Esta es una cita del discurso de Médici ante la Escuela Superior de Guerra.

${ }^{73}$ Incidentalmente, ha habido un considerable resurgimiento del integralismo, movimiento fascista nativo del Brasil, surgido en la década de 1930. Su dirigente, entonces y ahora, Plinio Salgado, después de proclamar hiperbólicamente que tenia 700.000 miembros de los cuales 100 eran diputados federales (en una Cámara de cerca de 400), fue interrogado sobre si el integralismo tenía representantes en el ejecutivo. El contestó: "Los hay, pero prefiero no citar nombres especificos. Nosotros no estamos aún en el gobierno, pero como están yendo las cosas... (¿qué quiere decir?)... Me refiero a la mentalidad. La mentalidad se está formando". "A volta do 'Chefe'", Veja, 13 de Mayo de 1970, página 23. Salgado actualmente es un diputado federal por la ARENA, en Säo Paulo. 
fascista $^{74}$ y que respete siquiera las mínimas aspiraciones participatorias del pueblo brasileño, incluyendo el establecimiento de procedimientos consensuales para la resolución de los conflictos de intereses y reglas predecibles para la sucesión en el poder, no será una tarea fácil, ni siquiera para los imaginativos tecnócratas legales que se afanan por servir a sus jefes militares.

\section{CONCLUSIÓN}

Los generales, coroneles y técnicos que han gobernado Brasil descle 1964 han avanzado un largo trecho hacia la institucionalización del régimen autoritario. Para hacerlo, no necesitaron introducir muchos cambios en las estructuras políticas formales ${ }^{75}$, limitándose a erradicar las prácticas competitivas y populistas de las instituciones existentes y a introducir en estas últimas un nuevo contenido político determinado desde arriba. Tampoco tuvieron que expandir dramáticamente la esfera de acción clel estado, o el tamaño del gasto público, sino que más bien se limitaron a diversificar su base financiera, a centralizar el proceso de formulación de decisiones y a hacer. un uso mucho más racional y autoritario de los instrumentos de política existentes.

Aparentemente, hasta ahora han logrado cumplir ampliamente los dos principales objetivos del régimen autoritario estable. Han conferido cada vez más autonomía al poder ejecutivo -independizándolo de la supervisión ejercida por las clases sociales organizadas o por otras instituciones competidoras- $y$, al hacerlo, han eliminado efectivamente todos los rivales que hubieran podido desafiar su hegemonía. Parafraseando a Marx, todas las clases sociales y los grupos políticos están postrados bajo la culata del fusil y el peso del plan nacional.

Irónicamente, los militares siguen insistiendo en su papel salvacionista, en su compromiso final con el establecimiento de una so-

${ }^{7}$ La excepción principal es la disolución forzosa del antiguo sistema multipartidista y la imposición del sistema de un partido y medio. Pero aun aqui, cuando observamos el nivel local, los cambios han sido más aparentes que reales. Consultar a Fanny Tabak, obra citada, para documentar la continuidad observable en Araraquara, São Paulo.

${ }^{76} \mathrm{La}$ excepción principal aqui es la creación de la Compañía de Pesquisa de Recursos Minerales (CPRM), que extiende el control gubernamental sobre la exploración y explotación de los minerales. Por otro lado, el régimen vendió la Fábrica Nacional de Motores (FNM) a intereses privados extranjeros $y$ ha creado una cantidad de consorcios mixtos, públicos-privados, en el campo de la petroquímica, un monopolio presumible de la Agencia Petrolera Estatal. (PETROBRAS). 
ciedad abierta y competitiva, que en todo caso funcionarian bajo su tutela. Pese a la retórica milenaria de la Doctrina de Seguridad. Nacional, no hay nada que indique que los golpistas de 1964 anticiparon o desearon el resultado que en definitiva produjeron. Ellos parecen haber creído sinceramente que estaban dando el primer paso hacia la demolición, y no hacia el perfeccionamiento, del sistema varguista. No es posible divisar ningún "gran designio" en lo que hicieron durante los próximos seis años, sino tan sólo una serie de reacciones y respuestas relacionadas entre sí a las crisis que iban emergiendo, cada una de las cuales reducía aún más la probabilidad de cualquier vuelta a un régimen democrático y civil en el futuro. La completa "portugalización", sin embargo, todavía no ha ocurrido. Como hemos visto, es necesario institucionalizar aún dos elementos estructurales claves. A través de la "educación cívica y moral", los gobernantes están empeñados en crear un conjunto de mentalidades obsecuentes, aunque existen razones para sospechar que este esfuerzo será tan infructuoso -y quizás tan contraproducente- como fueron los similares esfuerzos de indoctrinación durante Ia época del Estado Novo ${ }^{76}$. No existe evidencia de que los brasileños, por cínicos o desilusionados que parezcan, tengan el deseo permanente de renunciar a toda participación en las decisiones que afectan su vida colectiva o de apartarse deliberadamente de su búsqueda histórica de la democracia. Del mismo modo, los militares bien pueden señalar en forma oscura que el liberalismo está muerto o sobrepasado, pero ello no los exonera de la necesidad de inventar una nueva fórmula "auténticamente brasileña" para el estado revolucionario que ellos están dispuestos a continuar dirigiendo, tarea que sería mucho más difícil tratándose de un régimen que toda la población pudiera aceptar como legítimo. Inseguros acerca de sus propias reglas de decisión e inciertos acerca de su apoyo popular, Ios militares han reaccionado en forma exagerada a las amenazas reales e imaginarias que ven por todas partes, con un número creciente de medidas arbitrarias y represivas, haciendo cada vez más difícil la constitucionalización del régimen.

Incluso si sus actuales gobernantes pudieran llevar plenamente a cabo sus propósitos autoritarios, dudo mucho que la "portugalización" pueda ser una solución permanente para los problemas planteados por el desarrollo político del Brasil. Las fuentes más

${ }^{70}$ Consultar mi Interest Politics and Political Change in Brazil, páginas 59-69, para una discusión de la debilidad de las tentativas pasadas de indoctrinación deliberada en Brasil. Para algunas analogías españolas e italianas, ver Gino Germani, Political Socialization of Youth in Fascist Regimes: Italy and Spain, en S. P. Huntington y C. H. Moore (editores), Authoritarian Politics in Modern Society. Nueva Xork, Basic Books, 1970, páginas 339-379. 
obvias de dificultades yacen en el marco externo. Las pretensiones de gran potencia del Brasil, su sensibilidad frente a su imagen externa y su creciente dependencia frente a continuos flujos de capital y de tecnología extranjeros, lo hacen extremadamente vulnerables en este aspecto. La mayor parte de los regímenes autoritarios se consolidan a través de políticas autárquicas, no mercantilistas, aislándose en la medida de lo posible de las perturbaciones externas y promoviendo la imagen de un mundo hostil, incapaz de entender su peculiar destino como nación. Desde 1964, Brasil ha optado por el camino opuesto, cultivando deliberadamente los contactos y los recursos internacionales, públicos y privados. Si los inversionistas. privados extranjeros, los servidores públicos internacionales o los funcionarios de los Estados Unidos perdieran confianza en la capacidad de los militares brasileños para garantizar la estabilidad, o decidieran que un régimen autoritario prolongado no es el más apto para proteger sus intereses económicos y políticos, el sistema se vería en dificultades. Sería interesante, por ejemplo, observar la reacción de los militares brasileños si sus colegas de los Estados Unidos retiraran públicamente el mandato con que de facto los han investido, como guardianes del Mundo Libre y de la Civilización Occidental en el hemisferio sur. No hay muchas probabilidades de que esto ocurra, pero la hipótesis es estimulante.

La otra principal fuente de vulnerabilidad para el Brasil yace en el comportamiento global de la economía. Los últimos tres años demuestran que un régimen autoritario, incluso cuando actúa en forma arbitraria, no es incompatible con un considerable y sostenido dinamismo económico. El agotamiento de la sustitución de importaciones fácil, la existencia de capacidad productiva ociosa, la concentración del ingreso, el deterioro del nivel de vida popular, la limitada capacidad para importar, la inflación institucionalizada y el desempleo estructural tampoco han producido contradicciones insuperables. Hay, sin embargo, pocas indicaciones de que las politicas del régimen vayan a eliminar estas características del desarroIlo retrasado del Brasil. Una declinación en la tasa global de crecimiento -detonada, por ejemplo, por una caída en el comportamiento de las exportaciones- podría desinflar la burbuja de optimismo irreal que hoy predomina, y exagerar las desigualdades regionales, las tensiones de clase y los conflictos sectoriales. Sin embargo, hay pocas razones para esperar que tales problemas amenacen seriamente al régimen, con sus recursos financieros, su capacidad técnica y su relativa autonomía ante los vínculos de dependencia ya tradicionales. Su capacidad de maniobra para adaptar las políticas a las nuevas situaciones es considerable, y hay buenas razones para espe- 
rar que estos cambios se adopten en forma preventiva. Los indicadores sociales, las encuestas y un servicio de inteligencia eficiente le suministra la información que antes provenía de los medios de comunicación de carácter público y colectivo, mientras cabe esperar que un grupo de técnicos esclarecidos puedan hacer los necesarios ajustes marginales.

El elemento más agudo de vulnerabilidad radica dentro del régimen mismo, y no en sus relaciones con las potencias extranjeras ni en su responsabilidad frente a la ciudadanía. A causa de la atrofia de casi todas las asociaciones políticas y los canales de representación y de solución de conflictos, todos los grupos que desean influenciar el sistema político deben dirigirse directamente a los militares y, en menor medida, a los peldaños más altos de la burocracia civil. A menos que la disciplina organizativa y la unidad ideológica fueran extraordinariamente consistentes, esos llamados tenderán a despertar respuestas diferentes de parte de las distintas facciones del régimen. A medidas que estas brechas se ensanchan, al régimen le resultará cada vez más difícil efectuar cambios de política en forma gradual y pragmática, o responder en forma unitaria a las disminuciones o crisis en el comportamiento global del sistema.

Existe amplia evidencia de que tal faccionalismo existe. Ello se puso de manifiesto en forma aguda durante las tensas y prolongadas negociaciones referentes a la sucesión de Costa e Silva. Sería difícil decir si las bases de tales facciones se encuentran todavía sujetas a un proceso de cambio y superposición, de acuerdo con los grupos de edad, la región o el nivel de experiencia de sus componentes, o si por el contrario han comenzado a fusionarse dentro de seguimientos agregados y relativamente estables, cada uno de los cuales profesa distintos enfoques políticos, como por ejemplo, los nacionalistas, corporativistas, internacionalistas, profesionalistas, etc. Concediendo que el golpe o la transferencia pacífica del Poder Ejecutivo desde una de esas facciones a otra -como por ejemplo de los actuales internacionalistas a los grupos más nacionalistas- no podrían destruir por sí mismos el régimen autoritario, cabe reconocer sin embargo que ello bastaria para postergar su institucionalización. Es posible que en la lucha interna de las distintas facciones, algunos de los contendientes comience a apelar a los grupos no privilegiados, marginados de las élites, en forma típicamente populista. Irónicamente, desde que los militares comenzaron a trabajar tan intensamente para despolitizar a la ciudadanía, cada vez parece más claro que sólo mediante la politización de los militares ésta podría recuperar su papel político perdido. Es triste admitir que esto no 
constituye una gran protección frente a la osificación de las alternativas políticas y de la libre experimentación, que parece constituir el precio cobrado por el proceso de portugalización, a cambio de su respuesta no revolucionaria a las demandas de la modernización. 